\title{
UTILIZACIÓN DE MANO DE OBRA EN LA AGRICULTURA MEXICANA, 1940-1973
}

\author{
TERESA RENDóN \\ El Colegio de México
}

\section{INTRODUCĊIóN}

EN LAS ÁREAS RURALES, la agricultura constituye la actividad económica principal, aun cuando coexisten otras actividades económicas cuya importancia relativa en las distintas comunidades depende del nivel de ingresos, hábitos de consumo y tamaño de su población, así como de su dotación de recursos productivos y del acceso que se tenga a mercados que vayan más allá del ámbito local.

A fin de poder determinar la evolución de la principal actividad económica de las áreas rurales como fuente de ocupación, en este trabajo se presentan estimaciones de los requerimientos totales de mano de obra en la agricultura mexicana en 1940,1960 y 1973 mediante coeficientes técnicos por cultivo, en los cuales se consideran los factores que determinan de manera directa la utilización de mano de obra. Con estos resultados sólo se pretende evaluar la capacidad del sector para absorber mano de obra, pero no tienen ninguna implicación respecto del grado de ocupación de la población que trabaja en la agricultura, ya que se trata de un análisis sectorial y por lo tanto parcial de la actividad económica de dicha población. ${ }^{1}$

Debido a que un cambio en los requerimientos de mano de obra tiene distinto significado en términos de ingreso para la población trabajadora, según se satisfagan con mano de obra asalariada o con mano de cibra de los productores mismos y sus familias, de manera complementaria a la estimación de los requerimientos de mano de obra, se tratará de inferir hasta qué punto los cambios en dichos requirimientos han tenido lugar dentro de la agricultura capitalista cuya producción se base

1 Este tipo de resultados se usan con frecuencia para medir la subutilización de la fuerza de trabajo mediante la comparación de los requerimientos de mano de obra en la agricultura con la población económicamente activa dedicada a esa actividad, bajo el supuesto audaz de que todas las personas que integran esta última (o por lo menos los hombres mayores de cierta edad) estarían disponibles para trabajar en la agricultura durante todo el año. Véase por ejemplo: pREALC, El problema del empleo en América Latina: situación, perspectivas y politicas, o.I.T., Santiago, Chile, abril de 1976, pp. 261-265. 
en el trabajo asalariado $\longrightarrow$ o dentro de la economía campesina- que utiliza sobre todo trabajo familiar.

En México la estructura agraria está integrada por diversas formas de producción articuladas y dominadas por el modo de producción capitalista, entre las que predominan la' forma de producción capitalista y la economía campęsina. La empresa capitalista produce para el mercado con el fin de obtener ganancias, para lo cual explota la tierra con base en el trabajo de asalariados y acumula capital a través de inversiones de mediano y largo plazos. En cambio, en la unidad campesina el producto que se obtiene (al margen de la proporción que del mismo se comercialice), se destina a la satisfacción de las necesidades de la familia y a la reposición de los instrumentos de trabajo (no existe prácticamente acumulación de capital); la diferencia entre el valor de la producción y el costo, no es más que un "salario autoatribuido" ya que la explotación de la tierra se basa en el trabajo no remunerado de la familia, la contribución de jornaleros es restringida y sólo complementa al trabajo familiar en épocas en que éste es insuficiente. ${ }^{2}$

Así, mientras en una empresa capitalista determinada, un aumento en los requerimientos de mano de obra (derivado por ejemplo de la introducción de agua para riego que permite el uso más intensivo de la tierra y del resto de los factores productivos), significa un aumento en las oportunidades de empleo y de ingreso para quienes venden su fuerza de trabajo; en un predio campesino, un aumento en los requerimientos de mano de obra significa un mayor esfuerzo de la familia en el proceso productivo, el cual puede implicar o la participación de mayor número de familiares, o jornadas de trabajo mayores para algunos de ellos. Esto beneficiará a la familia campesina sólo en la medida en que el incremento en la producción compense cuando menos el esfuerzo adicional, siempre que no exista ocupación alternativa para esa fuerza de trabajo familiar que le reporte un mayor ingreso. ${ }^{3}$

2 A mayor abundamiento sobre este tema véase: Kirsten A. de Appendini y Vania Almeida Salles, "Agricultura capitalista y agricultura campesina en México (diferencias regionales en base al análisis de datos censales)", Cuadernos del Centro de Estudios Sociológicos, El Colegio de México, 1975, y de varios autores, $\mathrm{Ca}$ pitalismo y campesinado en México. Estudios de la realidad campesina, México, Secretaría de Educación Pública e Instituto Nacional de Antropología e Historia, 1976.

3 En investigaciones realizadas entre los sujetos del Plan Puebla, programa destinado a aumentar los rendimientos de maíz mediante la práctica de mejores métodos de cultivo, se ha encontrado que los campesinos se resisten a adoptar nuevas técnicas, cuando esto implica un aumento considerable en los requerimientos do mano de obra, en particular cuando las familias tienen pocos miembros en edad de trabajar. 


\section{Factores determinantes de la ABSOrción de MANo de OBRA}

En la agricultura, las necesidades de mano de obra están determinadas de manera directa por cuatro factores: la superficie agrícola, la composición de cultivos, los rendimientos físicos de los mismos y el grado de mecanización. Se verá entonces cómo ha cambiado en el tiempo la cantidad de mano de obra requerida para la producción, en función de los cambios en dichos factores.

Además, si se considera que las necesidades de mano de obra varían de manera considerable de un mes a otro, como consecuencia de la estacionalidad de la actividad agrícola, es conveniente analizar los efectos de la estacionalidad sobre la utilización de la fuerza de trabajo.

\section{Superficie agrícola}

Cualquier incremento en la superficie dedicada a la agricultura implicará por necesidad un aumento en la utilización de mano de obra, pero la magnitud de este aumento variará de acuerdo con la intensidad en el uso de mano de obra del cultivo o cultivos a que se destine la nueva superficie agrícola y del grado de mecanización de las labores agrícolas.

El aumento en la disponibilidad de agua para riego tiene un efecto similar al de un aumento en la superficie agrícola, pero además, posibilita la producción de cultivos más intensivos en el uso de mano de obra como hortalizas y frutales, y aumenta los requerimientos de mano de obra en la construcción de "regaderas" y bordos, limpia de canales y en la aplicación misma del agua. En adición, el riego tiene también un efecto positivo indirecto en la utilización de mano de obra, al aumentar los rendimientos de los cultivos, siempre y cuando la cosecha sea manual.

Además, si consideramos que para administrar cada hectárea cultivada se requieren cinco días-hombre, el aumento en la superficie agrícola origina un incremento proporcional en la mano de obra necesaria para sste fin. Sin embargo, los requerimientos de mano de obra para la administración agrícola no necesariamente pueden sumarse a los requerimientos para la producción misma, pues es bastante frecuente (en especial cn unidades productoras pequeñas) que administración y labores directas del cultivo se realicen de manera simultánea. Por este motivo, se analizan por separado ambos tipos de requerimientos de mano de obra.

\section{Rendimientos}

Las variaciones en la producción por hectárea que se obtienen en un cultivo determinado, provocan variaciones en el mismo sentido en la cantidad de mano de obra que se utiliza durante. la cosecha, cuando ésta se lleva a cabo en forma manual. 
Los rendimientos, en especial en las áreas temporaleras, están sujetos a las condiciones climatológicas, pero en general, en los distintos cultivos muestran una tendencia ascedente como consecuencia del uso de mejores técnicas, aun cuando esto no ha ocurrido de manera homogénea entre cultivos y entre regiones.

\section{Composición de cultivos}

La intensidad en el uso del factor referido varía de manera considerable entre cultivos, al margen del grado de mecanización que se emplee. Por ejemplo, cuando se usa tracción mecánica, una hectárea de algodón sequiere cinco veces más mano de obra que una hectárea de maíz y a su vez una hectárea de maíz absorbe casi el doble que una de trigo como puede verse al comparar los cuadros 1,2 y 3 en los que se presentan los requerimientos de mano de obra, maquinaria y animales por hectárea en México para estos tres cultivos en áreas de riego, bajo los tres grados de mecanización más frecuentes.

La intensidad en el uso de mano de obra de cada cultivo depende de las distintas labores que es necesario llevar a cabo para producirlo y de la medida en que estas labores se realicen a mano; por ejemplo en el caso del algodón, los deshierbes y la cosecha siempre son manuales.

\section{Tecnología}

Por último, la cantidad de mano de obra necesaria para la producción de un cultivo determinado, depende de la tecnología empleada. Debido a que sus repercusiones sobre la utilización de mano de obra son distintas, es necesario distinguir dos aspectos de la tecnología.

a) Grado de mecanización. Se define la mecanización como el proceso mediante el cual se sustituye energía animada por energía inanimada de la fuerza mecánica; por tanto, no se considera como tal la sustitución ascendente de los instrumentos de cultivo, como es el tránsito del arado de madera al arado de hierro. ${ }^{4}$

La interpretación que tantas veces se ha dado a la mecanización como indicador de desarrollo agrícola, resulta muy cuestionable, pues su consecuencia principal ha sido el desplazamiento de mano de obra sin que se haya probado su efecto positivo sobre los rendimientos físicos. La mecanización significa una sustitución de tracción animal y mano de obra no calificada por tracción mecánica y mano de obra calificada (tractoristas, pilotos, fumigadores, etc.); pero la sustitución de mano de obra no calificada por calificada implica además una reducción en los requerimientos de días-hombre, como puede verse al revisar los coefi-

4 Véase Luis Yáñez Pérez, Mecanización de la agricultura mexicana, México, Instituto Mexicano de Investigaciones Económicas, 1958. p. XV. 
Cuadro 1

Algodón: Coeficientes de MANo de obra no CAlificada, maQuinaria a Y ANIMALES PARA OPERACIONES ESTÁNDAR (Jornadas por hectáreas) $^{\mathrm{b}}$

\begin{tabular}{|c|c|c|c|c|c|c|c|}
\hline & \multicolumn{2}{|c|}{ Mecanizado } & \multicolumn{3}{|c|}{ Parcialmente mecanizado } & \multicolumn{2}{|c|}{ Ho mecanizado } \\
\hline & $\begin{array}{l}\text { Hano de } \\
\text { obra no } \\
\text { calificada }\end{array}$ & $\begin{array}{l}\text { Maqui } \\
\text { naria }\end{array}$ & $\begin{array}{l}\text { Mano de } \\
\text { obra no } \\
\text { calificada }\end{array}$ & $\begin{array}{l}\text { Mayui } \\
\text { nariaz }\end{array}$ & 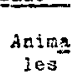 & $\begin{array}{l}\text { Thano de } \\
\text { obra no } \\
\text { calificaza }\end{array}$ & $\begin{array}{c}\text { Enima } \\
\text { les }\end{array}$ \\
\hline \multicolumn{8}{|l|}{ Primer mes } \\
\hline Labores preliminarea & - & 0.12 & - & $\begin{array}{lll}0 & 12 \\
0\end{array}$ & - & 1.0 & 2.0 \\
\hline Barbeoko & - & 0.5 & - & 0.5 & - & 3.0 & 6.0 \\
\hline Cruza & - & - & - & - & - & 2.5 & 5.0 \\
\hline Rastra & - & 0.2 & - & 0.2 & - & 0.5 & 1.0 \\
\hline Mivelación & - & 0.25 & - & 0.25 & - & 1.0 & 2.0 \\
\hline Limpia canales & 1.0 & - & 1.0 & - & - & 1.0 & 2.0 \\
\hline \multicolumn{7}{|l|}{$\frac{\text { Sepundo mes }}{\text { Regaderas }}$} & \\
\hline Bordeo & - & 0.2 & - & 0.2 & - & 2.0 & -0 \\
\hline Pega de bordos & 1.0 & - & 1.0 & - & - & - & - \\
\hline $\begin{array}{l}\text { Riego } \\
\text { Rastreo }\end{array}$ & 2.0 & -5 & 2.0 & 0.2 & $=$ & $\begin{array}{r}2.0 \\
2.0\end{array}$ & $\approx 0$ \\
\hline Sigmpra y fertilizam & & & & & & & \\
\hline $\begin{array}{l}\text { cion } \\
\text { Rodadil10 }\end{array}$ & 0.2 & 0.2 & -0.2 & 0.2 & - & $4 \cdot 0$ & - \\
\hline \multicolumn{8}{|l|}{$\begin{array}{l}\text { Rodadil10 } \\
\text { Terces mes } \\
\end{array}$} \\
\hline Desahije & 4.0 & - & 4.0 & - & - & 4.0 & - \\
\hline Cultivo & - & 0.2 & 2.0 & - & 4.0 & 2.0 & 4.0 \\
\hline Deshierioe : & 6.0 & - & 6.0 & - & - & 6.0 & . \\
\hline \multicolumn{8}{|l|}{ Aplración de insec- } \\
\hline \multirow{2}{*}{\multicolumn{8}{|c|}{ Cuarto mes }} \\
\hline & & & & & & & \\
\hline Fertilzzacion & $\overline{-}$ & 0.2 & $\begin{array}{l}2.0 \\
2.0\end{array}$ & $=$ & $\overline{4.0}$ & $\begin{array}{l}2.0 \\
2.0\end{array}$ & $\overline{4.0}$ \\
\hline $\begin{array}{l}\text { Cultivo } \\
\text { Deshierbe }\end{array}$ & 6.0 & $\because 2$ & 6.0 & $=$ & 4.0 & $\begin{array}{l}2.0 \\
6.0\end{array}$ & - \\
\hline 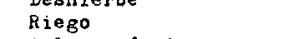 & 4.0 & - & 4.0 & - & - & 4.0 & - \\
\hline Aplicacion de unsec- & & & & & & & a \\
\hline \multicolumn{8}{|l|}{$\begin{array}{l}\text { ticidas } \\
\text { guinto mes }\end{array}$} \\
\hline$\frac{\text { Guinto mes }}{\text { cultivo }}$ & - & 0.2 & 2.0 & - & 4.0 & 2.0 & 4.0 \\
\hline Deshierbe & 6.0 & -2 & 6.0 & $\overline{-}$ & $\because$ & 6.0 & - \\
\hline \multirow{2}{*}{\multicolumn{8}{|c|}{$\begin{array}{l}\text { Dos riegos } \\
\text { Aplicacion de insec- }\end{array}$}} \\
\hline & - & - & 6.0 & - & - & 5.0 & - \\
\hline \multicolumn{8}{|l|}{$\begin{array}{l}\text { riclaas } \\
\text { Sexto mes }\end{array}$} \\
\hline $\begin{array}{l}\text { Deshierbe } \\
\text { Riego }\end{array}$ & $\begin{array}{l}6.0 \\
2.0\end{array}$ & z & $\begin{array}{l}6.0 \\
2.0\end{array}$ & $=$ & $\bar{z}$ & 6.0 & - \\
\hline Aplicacion de insec- & \multicolumn{7}{|c|}{$\begin{array}{l}\text { Riego } \\
\text { aplicacion de insec- }\end{array}$} \\
\hline \multirow{2}{*}{\multicolumn{8}{|c|}{$\begin{array}{l}\text { ticidas of } \\
\text { Septimo mes }\end{array}$}} \\
\hline & & & & & & & \\
\hline $\begin{array}{l}\text { Cosecha } d / \text { loos tone } \\
\text { lada) }\end{array}$ & 12.0 & - & 12.0 & - & - & 12.0 & - \\
\hline \multirow{3}{*}{\multicolumn{8}{|c|}{ Octavo mes }} \\
\hline & & & & & & & \\
\hline & & & & & & & \\
\hline $\begin{array}{l}\text { Iada) } \\
\text { Acarreo }\end{array}$ & $\stackrel{12.0}{-}$ & 0.12 & $\begin{array}{r}12.0 \\
2.0\end{array}$ & 4.0 & z- & $\begin{array}{r}12.0 \\
2.0\end{array}$ & $\therefore 0$ \\
\hline \multirow{2}{*}{\multicolumn{8}{|c|}{$\frac{\text { Hoveno mes }}{\operatorname{cosecha} \text { d (por tone }}$}} \\
\hline & & & & & & & \\
\hline$\underset{A \operatorname{cad} a)}{\cos r 00}$ & 12.0 & - & 12.0 & - & $=$ & 12.0 & $\therefore 0$ \\
\hline Total de mano de obraf & 123.2 & - & 176.2 & - & - & 132.0 & - \\
\hline
\end{tabular}

Fuente: L. Ma. Bassoco y T. Rendón, "Jornadas de mano de obra no calificada, maquinaria y animales requeridos menstialmente por hectárea bajo tres grados de mecanización" (Mimeo.).

a Los coeficientes de mano de obra calificada (tractorista) corresponden a los coeficientes de maquinaria.

b Jornadas de ocho horas.

c Con mecanización total la aplicación de insecticidas para el algodón suele hacerse por avión.

d Normalmente la cosecha cubre tres meses consecutivos con 30,50 y $20 \%$ respectivamente.

c Considerando un rendimiento de 6916 toneladas por hectárea de algodón en hueso que corresponde a la media de los años 1970-1974. 
Cuadro 2

MAíz: COEFICIENTES DE MANO dE OBRA No CALIFICADA, MAQUINARIA a Y ANIMALES PARA OPERACIONES AGRÍCOLAS ESTÁNDAR

Jornadas por hectúreas)

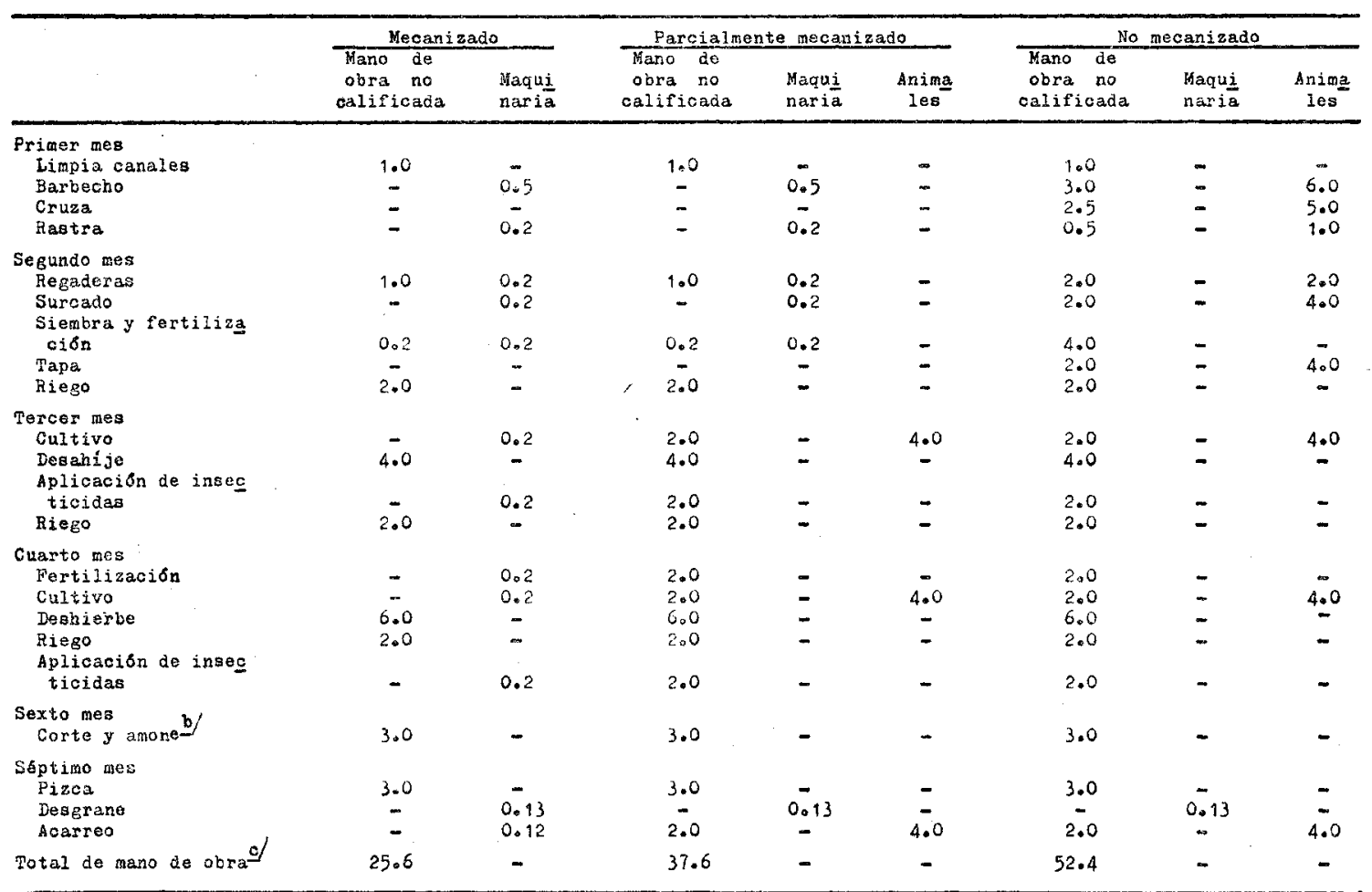

a Los coeficientes de mano de obra calificada (tractorista) corresponden a los coeficientes de maquinaria.

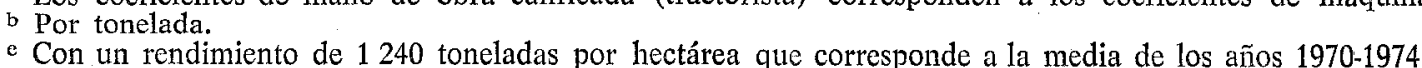




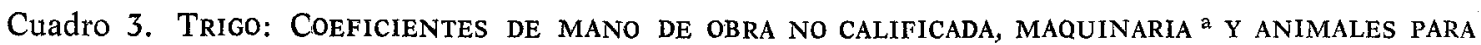
OPERACIONES AGRÍCOLAS ESTÁNDAR (JORNADA POR HECTÁREA)

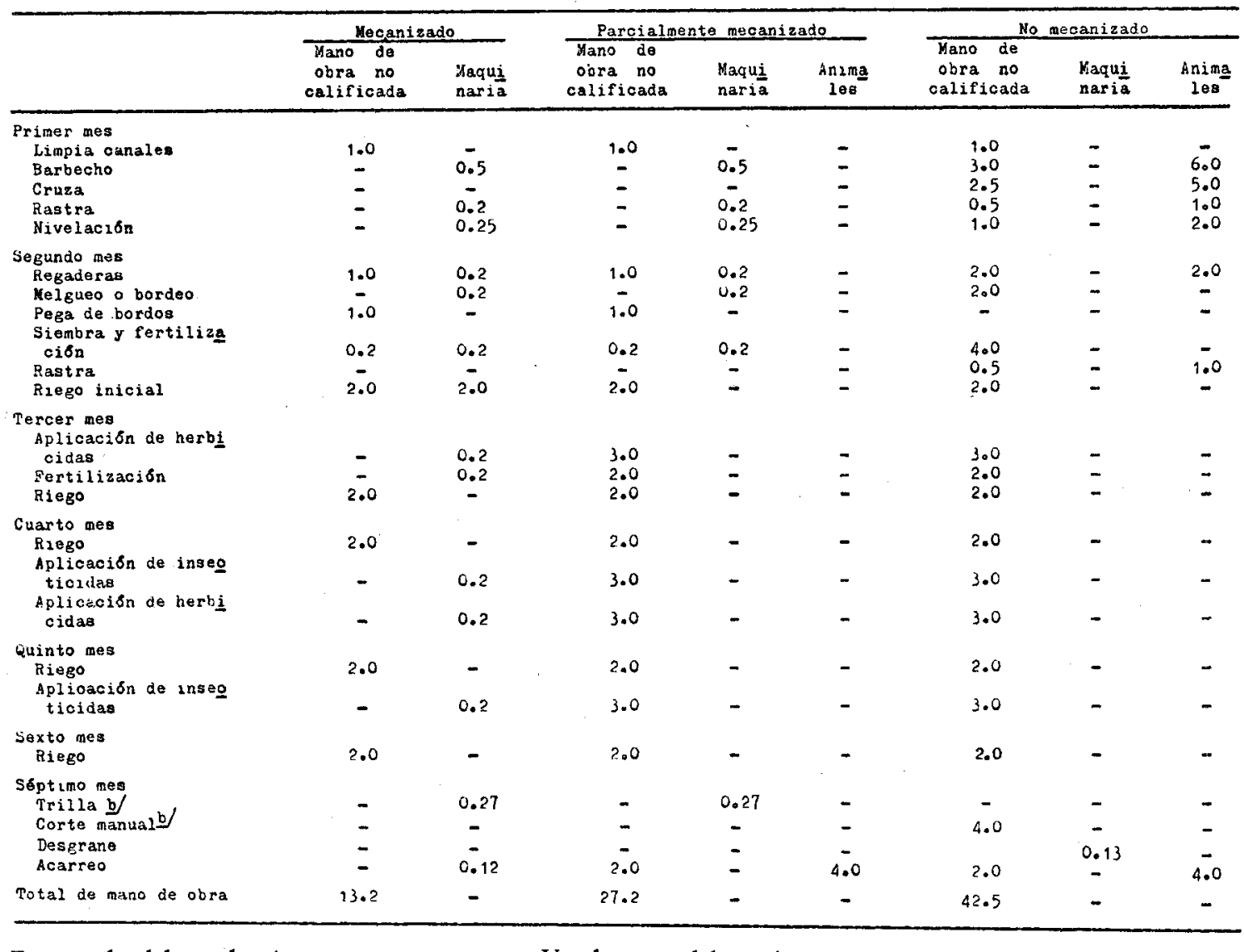

Fuente: la del cuadro 1.

a Ver la nota del cuadro 1.

b Por tonelada. 
cientes técnicos de mano de obra y maquinaria para un mismo cultivo con diferentes grados de mecanización (véanse los cuadros 1,2 y 3).

b) Métodos de cultivo y utilización de ciertos insumos como abonos o fertilizantes, insecticidas y semillas mejoradas. La realización de ciertas labores agrícolas (que pueden llevarse o no a cabo para la producción de un cultivo) como son el barbecho y los deshierbes, así como la utilización de fertilizantes e insecticidas, tienen un efecto positivo en la absorción de mano de obra, cuya magnitud depende del grado de mecanización que se emplee. Debido a que estas prácticas agrícolas tienden a elevar los rendimientos, se logra también un efecto positivo indirecto sobre el empleo como ocurre con el riego.

De esta manera, los cambios en la cantidad de trabajo necesaria para la producción agrícola son el resultado del efecto combinado de los cambios ocurridos en estos factores determinantes.

\section{Estacionalidad}

Otro aspecto importante que presenta el empleo agrícola es el de la estacionalidad, derivado de la naturaleza misma de la actividad. Los requerimientos de mano de obra varían según las labores que sea necesario realizar en las distintas etapas del proceso; como es bien sabido, los meses de mayor demanda de mano de obra son los correspondientes a la cosecha. ${ }^{5}$ Así, la absorción mensual de dicho factor está determinada por las fechas de siembra y de cosecha de los distintos cultivos que se producen en las diferentes regiones agrícolas del país, dados el grado de mecanización y los rendimientos físicos de los cultivos.

El problema de la estacionalidad es más crítico en las áreas de temporal (que abarcan el grueso de la superficie agrícola del país) donde sólo es posible obtener un cultivo al año. Esto induce a los jornaleros y grupos cada vez más numerosos de campesinos (privados y ejidales) a vender su fuerza de trabajo en distintos predios y a realizar a menudo migraciones constantes de una región a otra; o a complementar su ingreso mediante la realización de actividades no agrícolas (dentro o fuera de su comunidad) durante las etapas en que los cultivos no requieren atención.

\section{ESTIMACIONES}

Con estos criterios se analizará la evaluación de la absorción de mano de obra en la agricultura durante el período 1930-1973, a partir de estimaciones de los requerimientos totales de mano de obra para los distintos cultivos. Estas estimaciones se basan en coeficientes de insumoproducto por cultivo (dados en días-hombre por hectárea).

5 Los cambios en los requerimientos de mano de obra en los distintos meses del año se ilustran en la gráfica 2. 
En atención al grado de dinamismo seguido por la actividad en cuestión, se distinguen dos subperíodos: 1940-1960, que puede considerarse de auge agrícola, y 1960-1973 en el que se registra un estancamiento y por tanto una reducción drástica en la generación de empleo.

Para el primer subperíodo las estimaciones fueron tomadas del libro de Sergio Reyes Osorio et al., ${ }^{6}$ en las cuales se consideran coeficientes de insumo-producto constantes en el tiempo, ${ }^{7}$ por lo cual no se captan los efectos que sobre la absorción de mano de obra deben haber tenido los cambios en el grado de mecanización y los rendimientos físicos de los cultivos; sin embargo permiten tener un conocimiento aproximado de los cambios en dicha absorción, ya que incluyen los efectos que tuvieron sobre la misma, el aumento en la superficie agrícola y el cambio en la composición de cultivos.

Para el período 1960-1973, las estimaciones se hicieron a partir de coeficientes técnicos tomados de un modelo de programación agrícola, 1o que permitió disponer de información suficiente para aislar el peso relativo que cada uno de los factores determinantes tiene en el cambio en la utilización de mano de obra. ${ }^{8}$

\section{Período $1940-1960$}

a) Absorción de mano de obra a nivel nacional. De 1940 a 1960 , la agricultura mexicana mantuvo un dinamismo capaz de satisfacer la demanda interna de productos agrícolas y de contribuir de modo sustancial al abastecimiento de divisas necesarias para cubrir las importaciones. De la misma manera, los requerimientos de mano de obra crecieron a un ritmo que puede considerarse elevado, como se observa en el cuadro 4.

Durante estos dos decenios, el efecto positivo que sobre la utilización de mano de obra tuvieron los importantes incrementos de la superficie agrícola, se vio fortalecido, sobre todo en el decenio de los cuarentas, por un efecto positivo del cambio en la composición de cultivos, ya que en general los cultivos cuya superficie registró los mayores incrementos fueron los más intensivos en el uso de mano de obra (algodón, hortalizas, frutales y plantaciones). Esto se refleja en una disminución de la

6 S. Reyes Osorio, et al., Estructura agraria y desarrollo agrícola en México, México, Fondo de Cultura Económica, 1974.

7 Los coeficientes utilizados en estas estimaciones se basan en coeficientes técnicos correspondientes al año de 1956, derivados de una investigación en predios agrícolas. Esto implica una sobreestimación de la absorción de mano de obra en 1940 en cuanto a mano de obra requerida en fertilización y cosecha, y una subestimación en cuanto a grado de mecanización y no es posible derivar en qué medida estos efectos podrían compensarse.

8 Sobre este modelo, véase Louis M. Goreux y Alan S. Manne (Comps.), MultiLevel Planning: Case Studies in Mexico, Amsterdam, North-Holland Publishing Co., 1973 (Parte IV, en especial los Capítulos 1 y 2). 
'Cuadro 4

MÉxico: Producto agrícola y absorción de maNo de obra EN LA AGRICULTURA

\begin{tabular}{|c|c|c|c|c|c|}
\hline \multirow[b]{2}{*}{1} & \multirow{2}{*}{$\begin{array}{l}\text { Frodicto agricola } \\
\text { (a precio de } 1960 \text { ) }\end{array}$} & \multicolumn{4}{|c|}{$\begin{array}{l}\text { Requerimientos de mano de obra } \\
\text { (dias-hombre al año) }\end{array}$} \\
\hline & & $\begin{array}{c}\text { Total } \\
\text { nacional }\end{array}$ & $\begin{array}{l}\text { Predios } \\
\text { mayores de } \\
5 \text { hectareas }\end{array}$ & $\begin{array}{l}\text { Predios de } \\
5 \text { hectareas } \\
\text { o menos }\end{array}$ & $E_{j i d o s}$ \\
\hline $1940-1960$ & 5.7 & 3.1 & 3.6 & 1.2 & 2.9 \\
\hline $1960-1973$ & 2.7 & 1.4 & 0.0 & -4.0 & 3.1 \\
\hline
\end{tabular}

Fuentes: Producto agrícola: Banco de México, Informes anuales; Requerimientos de mano de obra 1940-1960, con base en Estructura agraria..., op. cit., pp. 1111, 1112,1115 y 1116 (sin considerar la correspondiente a superficies perdidas); requerimientos de mano de obra 1960-1963, con base en el cuadro 6 .

importancia relativa de los cultivos tradicionales en cuanto a absorción de mano de obra (véase el cuadro 5).

Como ya se indicó, estas cifras no reflejan el efecto positvio que sobre la utilización de mano de obra debe haber provocado el aumento sin precedente de los rendimientos físicos de los cultivos principales, registrado entre 1946 y 1955; tampoco reflejan el efecto negativo del acelerado proceso de mecanización de la agricultura capitalista del norte y del centro del país, que se inició a fines del decenio de los cuarentas.

Otro efecto del aumento de la superficie dedicada a la agricultura fue el incremento de los requerimientos de mano de obra para la administración de esta actividad. Estos requerimientos crecieron a una tasa media anual de $2.5 \%$ entre 1940 y 1950 y de $2.3 \%$ en el decenio siguiente.

Como se aprecia en el cuadro 6 , como consecuencia del dinamismo agrícola, la utilización de mano de obra creció a una tasa media anual de $3.2 \%$ durante 1940-1950 y de $3.0 \%$ en 1950-1960 (además del incremento en los requerimientos de mano de obra para administración), a pesar de lo cual la población económicamente activa (PEA) dedicada principalmente a las actividades agropecuarias se incrementó a un ritmo anual medio mucho menor: $2.3 \%$ entre 1940 y 1950 y $0.5 \%$ en el decenio siguiente (según los censos de población), ${ }^{9}$ a la vez que la migración rural-urbana adquiría dimensiones importantes. En gran me-

9 Los censos de población subestiman la PEA dedicada a actividades agropecuarias, debido a que establecen límites de edad y tiempo trabajado, cuando se sabe que en este tipo de actividades la participación de menores y de personas que trabajan tiempo parcial es importante. Sin embargo, puede tomarse como un indicador aproximado de la medida en que la agricultura constituye la fuente principal de ocupación de aquellos miembros de la familia que destinan la mayor parte de su tiempo a actividades económicas. Los censos agrícolas no imponen restricción sobre edad o tiempo trabajado, pero captan información sobre personal ocupado sólo a partir de 1950 , año en el cual tal cifra parece subestimada. 


\section{Cuadro 5}

ABsorción de MANo de ObRa POR PRINCIPALES CUltivos, SEGÚN gRUPOS DE TENENCIA, 1940 y 1960 (Miles de dias-hombre al año)

\begin{tabular}{|c|c|c|c|c|c|c|c|c|}
\hline 1 & \multicolumn{2}{|c|}{ Total } & \multicolumn{2}{|c|}{$\begin{array}{l}\text { En predios mayores } \\
\begin{array}{c}\text { de } 5 \text { hectareas } \\
\text { dbsog }\end{array}\end{array}$} & \multicolumn{2}{|c|}{$\begin{array}{l}\text { En predios de } 5 \text { hec } \\
\text { táreas o menos } \\
\text { thaclitog }\end{array}$} & \multicolumn{2}{|c|}{ Ejidos } \\
\hline & & & $\because$ & & & & & \\
\hline \multicolumn{9}{|l|}{ For cultivos } \\
\hline Total & $271 \quad 184$ & 100.0 & 121805 & 100.0 & 25343 & 100.0 & 124036 & 100.0 \\
\hline $\begin{array}{l}\text { Mafz } \\
\text { Frijol } \\
\text { Cafe } \\
\text { Caña de aztoar } \\
\text { Algodón } \\
\text { Otros }\end{array}$ & $\begin{array}{rl}132 & 168 \\
12 & 880 \\
24 & 327 \\
12 & 600 \\
10 & 541 \\
78 & 668\end{array}$ & $\begin{array}{r}48.7 \\
4.7 \\
9.0 \\
4.6 \\
3.9 \\
29.1\end{array}$ & $\begin{array}{rl}52 & 359 \\
4 & 777 \\
15 & 073 \\
4 & 548 \\
4 & 753 \\
40 & 295\end{array}$ & $\begin{array}{r}43.0 \\
3.9 \\
12.4 \\
3.7 \\
3.8 \\
33.2\end{array}$ & $\begin{array}{r}17472 \\
349 \\
2797 \\
760 \\
160 \\
3805\end{array}$ & $\begin{array}{r}68.9 \\
1.4 \\
11.0 \\
3.0 \\
0.6 \\
15.1\end{array}$ & $\begin{array}{rl}62 & 337 \\
7 & 754 \\
6 & 457 \\
7 & 292 \\
5 & 648 \\
34 & 548\end{array}$ & $\begin{array}{r}50.3 \\
6.3 \\
5.2 \\
5.9 \\
4.6 \\
27.7\end{array}$ \\
\hline \multirow[t]{2}{*}{ Por administracion } & 36565 & & 15225 & & 3745 & & 17595 & \\
\hline & \multicolumn{8}{|c|}{1960} \\
\hline \multicolumn{9}{|l|}{ Por cultivos } \\
\hline Total & 499335 & 100.0 & $248 \quad 582$ & 100.0 & 32269 & 100.0 & 218484 & 100.0 \\
\hline $\begin{array}{l}\text { Malz } \\
\text { Frijol } \\
\text { Cafe } \\
\text { Caña de azocar } \\
\text { Algodón } \\
\text { Otros }\end{array}$ & $\begin{array}{rl}188 & 429 \\
32 & 857 \\
52 & 651 \\
32 & 359 \\
39 & 112 \\
153 & 927\end{array}$ & $\begin{array}{r}37.7 \\
6.6 \\
10.5 \\
6.5 \\
7.8 \\
30.9\end{array}$ & $\begin{array}{ll}80783 \\
15497 \\
30859 \\
15883 \\
25284 \\
80276\end{array}$ & $\begin{array}{r}32.5 \\
6.2 \\
12.4 \\
6.4 \\
10.2 \\
32.3\end{array}$ & $\begin{array}{r}18617 \\
1011 \\
6335 \\
946 \\
\quad 173 \\
5 \quad 887\end{array}$ & $\begin{array}{r}57.7 \\
3.1 \\
19.6 \\
2.9 \\
0.5 \\
16.2\end{array}$ & $\begin{array}{ll}89 & 029 \\
16 & 349 \\
15 & 457 \\
15 & 530 \\
13 & 655 \\
68 & 464\end{array}$ & $\begin{array}{r}40.7 \\
7.5 \\
7.1 \\
7.1 \\
6.2 \\
31.4\end{array}$ \\
\hline Por administracion & 60455 & & 28790 & & 4305 & & 27360 & \\
\hline
\end{tabular}

Fuente: Con base en datos de S. Reyes Osorio, R. Stavenhagen et al., Estructura agraria..., op. cit., pp. $1111,1112,1115$ y 1116 (sin considerar superficies perdidas). 


\section{Cuadro 6}

Población ECONÓMICAMENTE ACTIVA (PEA) DE 12 Y MÁs AÑos EN ACTIVIDAdES Agropecuarias $Y$ NO AGROPECUARIAS Y REQUERIMIENTOS MANO DE OBRA EN LA AGRICULTURA

\begin{tabular}{|c|c|c|c|c|c|c|c|}
\hline & \multicolumn{4}{|c|}{ Absolutos } & \multicolumn{3}{|c|}{ Tasa media de incremento anual } \\
\hline & $\overline{1940}$ & 1950 & 1960 & 1970 & $1940-1950$ & $1950-1960$ & $1960-1970$ \\
\hline PEA Total & 5858 & 8. 272 & 10213 & 12955 & 3.5 & 2.0 & 2.4 \\
\hline $\begin{array}{l}\text { PEA en actividades no agro } \\
\text { pecuarias }\end{array}$ & 2027 & 3448 & 5165 & 7662 & 5.5 & 4.0 & 4.0 \\
\hline $\begin{array}{l}\text { PEA en actividades agrope- } \\
\text { cuarias }\end{array}$ & 3831 & 4824 & 5048 & 5293 & 2.3 & 0.5 & 0.5 \\
\hline $\begin{array}{l}\text { Requerimientos de mano de } \\
\text { obra (directa) en la agri } \\
\text { cultura a }\end{array}$ & - & - & - & - & 3.2 & 3.0 & $104^{\mathrm{b} /}$ \\
\hline $\begin{array}{l}\text { Mes de máxima ocupacion } \\
\text { (agosto) }\end{array}$ & 1824 & 3359 & 3843 & $4606^{\mathrm{C}}$ & - & - & - \\
\hline $\begin{array}{l}\text { Yes do mfnima ocupación } \\
\text {, (septiembre) }\end{array}$ & 592 & 1090 & 1247 & $1494^{\circ}$ & - & $=$ & - \\
\hline $\begin{array}{l}\text { Requerimientos de mano de } \\
\text { obra para aministracion } \\
\text { do la actividad agricola }\end{array}$ & 139 & 179 & 225 & 279 & 2.5 & 2.3 & $1.7^{b /}$ \\
\hline
\end{tabular}

Fuente: Población económicamente activa para 1940 y 1950: Dirección General de Estadística, SIC, Censos de población; para 1960 y 1970. Oscar Altimir, DEMOGRAFía Y ECONOMía, Núm. 22, 1975; requerimientos de mano de obra para 1940 y 1950: Estructura Agraria, op. cit., pp. 1111-1116 (sin considerar lo correspondiente a superficies perdidas); requerimientos de mano de obra para 1960 y 1973, cuadro 9. a Los requerimientos de mano de obra (meses-hombre), se obtuvieron al dividir la suma de días-hombre
requeridos para todos los cultivos entre 22, bajo el supuesto de que éste es el número medio de días hábiles al mes, con lo cual se obtiene meses-hombre al año, cifra que a su vez se multiplica por los porcientos correspondientes a los meses de máxima y mínima ocupación.

b Corresponde al período 1960-1973.

c Corresponde a 1973

d Años-hombre. 
dida ambos hechos son atribuibles al dinamismo de los otros sectores de actividad, lo que trajo consigo una notable expansión de las oportunidades de empleo no agrícola durante estos dos decenios, pero reflejan también la insuficiencia de los ingresos (monetarios y no monetarios) de muchas familias rurales, lo que obliga a sus miembros a buscar otras actividades complementarias o sustitutivas.

De esto se deduce que si bien durante este período, el sector agrícola fue capaz de satisfacer la demanda interna (efectiva) de productos agrícolas y aún de abastecer divisas que apoyaran el proceso de industrilización - para lo cual utilizó una cantidad creciente de mano de obra- no constituyó una fuente de trabajo satisfactoria.

Según cálculos basados en el Censo de Población de 1960, el ingreso medio mensual era de 356 pesos por trabajador agrícola y de 800 pesos por trabajador no agrícola ${ }^{10}$ (sin incluir ingresos no monetarios). En concordancia con estas cifras, de acuerdo con la encuesta sobre ingresos y gastos familiares realizada por el Banco de México en 1963,,11 las familias con ingresos más bajos eran aquellas cuyo jefe se dedicaba a la agricultura, las cuales percibían un ingreso medio mensual de 755 pesos (a precios de 1960), mientras para las familias cuyo jefe se dedicaba a actividades no agrícolas, tal ingreso era de 1559 pesos. Estas cifras incluyen ingresos no monetarios, es decir autoconsumo y pagos en especie, así como los ingresos de todos los miembros de la familia cualquiera que sea su origen.

Si bien puede decirse que los ingresos de las familias que viven principalmente de la agricultura son en general muy bajos, esto es aún más crítico entre las familias cuyo jefe es jornalero del campo, pues para éstas el ingreso medio mensual era de 460 pesos en 1963 (a precios de 1960).

La explicación del contraste entre el dinamismo agrícola y los bajos niveles de retribución de los trabajadores agrícolas, parece encontrarse en la estructura agraria prevaleciente.

La estuctura agraria, junto con la política de fomento agrícola propiciaron, a partir de 1940, el desarrollo de una agricultura capitalista a la cual puede atribuirse el dinamismo agrícola mencionado y de cuyo comportamiento dependen principalmente las oportunidades de ocupación de los jornaleros del campo. Pero las empresas capitalistas, pese a que concentran una proporción importante del ingreso agrícola, constituyen sólo una mínima parte de los productores agrícolas. La mayor parte de las unidades productoras son de tipo familiar, las que en general no obtienen de su actividad agrícola los ingresos necesarios para cubrir sus necesidades de consumo y reponer sus instrumentos de trabajo, por lo que se ven obligadas a realizar actividades económicas com-

$10 \mathrm{~S}$. Reyes Osorio, et al., op. cit., p. 89.

11 Banco de México, Oficina de Proyecciones Agrícolas, Encuesta sobre ingre. sos y gastos familiares en México-1963, Banco de México, 1966. 
plementarias. En 1960, el 3.3\% del total de predios (privados y ejidales) concentraban el $54.3 \%$ del valor de la producción agrícola, con un valor de más de 25000 pesos anuales por predio, mientras al $96.7 \%$ restante de los predios les correspondía el $45.7 \%$ del valor de la producción agrícola total (con menos de 25000 pesos anuales por predio). ${ }^{12}$

Es importante señalar que dentro de este último grupo, más de la mitad de los productores percibía ingresos brutos inferiores a mil pesos al año.

Por otra parte, existe un grupo cada vez mayor de jornaleros sin tierra, la mayor parte de los cuales no logran encontrar ocupación agrícola durante todo el año, comó consecuencia de la estacionalidad que caracteriza a esta actividad, no obstante que se movilicen entre predios y aun entre regiones. Además, los salarios que perciben los jornaleros del campo son casi siempre inferiores al salario mínimo establecido legalmente, ${ }^{13}$ to que les cierra toda posibilidad de ahorrar y permanecen inactivos durante los períodos de menor actividad agrícola, viéndose obligados (como en el caso de los agricultores de menores ingresos) a buscar ocupaciones complementarias, dentro o fuera de su localidad de residencia.

Resulta importante señalar que durante los años cuarenta, el dinamismo agrícola se tradujo en una situación favorable para los jornaleros, dado que los jornales representaban el $40 \%$ del gasto agrícola total en 1950. Sin embargo, en el decenio siguiente, la política de tecnificación iniciada durante el sexenio de Miguel Alemán (1947-1952), dio como resultado un rápido incremento de la composición orgánica del capital, con lo que para 1960 los salarios sólo representaban el 28\% del mencionado gasto y se reducen así las posibilidades de ocupación para los jornaleros, to cual coincide con la reducción de la tasa de incremento de la PEA que tenía como ocupación principal la agricultura.

b) Absorción de mano de obra por grupos de tenencia de la tierra. Al analizar los cambios en la utilización de mano de obra por grupos de tenencia de la tierra, como se observa en el cuadro 4, éstos se originaron sobre todo en los predios privados mayores de cinco hectáreas debido a que el mayor incremento en la superficie agrícola, en especial la de riego, se dio en predios pertenecientes a este grupo.

Las importantes obras de riego que se llevaron a cabo durante esta época, al favorecer de manera preferente a los predios privados grandes, condujeron a que el efecto positivo del cambio en la composición de cultivos se concentrara básicamente en este tipo de predios, además de que la producción de los cultivos intensivos en mano de obra que por lo ge-

12 S. Reyes Osorio, et al., ibid., p. 953.

13 En una encuesta realizada por El Colegio de México en 1975 en 13 localidades rurales distribuidas en distintos estados del país, se encontró que en 11 de esas localidades el salario medio agrícola era inferior al mínimo legal establecido para ese año $y$, en seis localidades, el salario pagado no llegaba a $60 \%$ de dicho mínimo. 
neral son los de precio mayor en el mercado, sólo es factible para aquellas unidades productoras que cuentan con recursos suficientes para cubrir los costos en que es necesario incurrir y las únicas que tienen acceso fácil al mercado de este tipo de productos.

Mientras la absorción de mano de obra en predios privados mayores de cinco hectáreas creció a una tasa media anual de $3.6 \%$, en los predios menores este incremento fue apenas del $1.2 \%$ debido en mayor medida a un modesto aumento en la superficie cosechada, ya que su estructura por cultivos se modifica de manera muy leve. Entre 1940 y 1960, este grupo pierde importancia: el número de predios menores de 5.1 hectáreas disminuyó de 800 a 721 , lo cual parece indicar que la concentración de predios y el abandono de predios muy pequeños, superaron el efecto de la división de la tierra resultante de la presión demográfica.

Aun cuando por la amplitud del grupo no es posible afirmar que los predios mayores de cinco hectáreas representan en su conjunto a la agricultura capitalista, puede afirmarse que las tendencias señaladas se deben al dinamismo de las empresas capitalistas que disponen de extensiones de tierra relativamente grandes como para permitir una explotación redituable; en tanto, es razonable suponer que los predios menores de cinco hectáreas forman parte de la economía campesina.

En el caso de los ejidos, donde los requerimientos de mano de obra aumentaron a una tasa media anual de $2.9 \%$, el principal factor determinante fue el aumento en la superficie agrícola, derivado del constante reparto agrario que bajo esta forma de tenencia tuvo lugar durante estos dos decenios. Dada la menor diversificación de cultivos en los ejidos, el efecto empleo resultante del cambio en la composición de cultivos fue menos importante que en el caso de los predios privados mayores de cinco hectáreas. La explicación parece encontrarse en el hecho de que dentro de los ejidos, la incidencia de parcelas pequeñas es alta; en 1960, el $34.5 \%$ de los ejidatarios poseía parcelas menores de 4.1 hectáreas. ${ }^{14}$

El ejido en realidad constituye, en la generalidad de los casos, una forma encubierta de explotación privada cuya forma de producción puede ser capitalista o de economía campesina, lo cual depende principalmente de la disponibilidad de recursos productivos. Por lo reducido de la extensión con que cuentan la mayor parte de las parcelas ejidales, podría decirse que son unidades campesinas, además de que en su mayoría no permiten a los ejidatarios y sus familias vivir sólo del producto obtenido de la agricultura. De acuerdo con los censos agrícolas de 1950 y 1960 , una elevada proporción de ejidatarios trabajan como jornaleros en otros predios o realizan otros oficios.

Sin embargo, existen ejidos que al haber sido dotados con parcelas de tamaños y calidad redituables, forman parte de la agricultura capita-

14 Dirección General de Estadística, IX Censo Agrícola Ganadero y Ejidal, 1960. Resumen General, cuadro 41. 
lista como es el caso de varios ejidos del norte del país, los cuales además se han visto favorecidos por el crédito otorgado por la banca oficial.

c) Absorción de mano de obra por regiones. Aun cuando en todo el país se registraron incrementos en la absorción de mano de obra como consecuencia de la apertura de nuevas tierras al cultivo, los mayores incrementos se registraron en la parte norte ( $\mathrm{y}$ en especial el noroeste) en donde se construyeron grandes obras de irrigación en los años cuarentas. Como esta nueva tierra irrigada se repartió de manera preferente en forma privada y en unidades de explotación relativamente grandes, se estimuló la acumulación de capital y la diversificación de cultivos, con lo que surge una agricultura capitalista moderna. Fueron estas regiones las beneficiadas del auge algodonero de los cincuentas, lo que las convirtió en zonas de atracción de migrantes tanto temporales como definitivos procedentes de las regiones de agricultura atrasada.

La agricultura del centro del país, por su situación geográfica respecto del principal centro de consumo, mostró un marcado dinamismo, pero éste provino una vez más de las empresas capitalistas que sustituyeron la producción de granos por hortalizas y alfalfa, pero la agricultura capitalista no constituye la forma de producción predominante, pues fue precisamente en las entidades federativas del centro donde la concentración demográfica existente en el momento del reparto agrario, condujo al minifundismo y con ello a la economía campesina de infrasubsistencia. En estas entidades, en 1960 más del 90\% de los propietarios privados poseían predios inferiores a 5.1 hectáreas, muchos de los cuales habían desaparecido para 1970.

En esta región, la solución al problema de bajos ingresos de la población rural esta lejos de encontrarse en la agricultura, ya que los recursos naturales, de por sí escasos, se ven cada vez más agotados por su destino a fines urbanos. Un ejemplo claro de lo anterior es el abatimiento de los mantos freáticos.

La solución más frecuente que ha encontrado la población rural de las entidades del Centro, es la migración pendular y definitiva a las áreas urbanas, la cual es cada día más frecuente. En una encuesta realizada en el Estado de México en 1972, se encontró que la mayor parte de los campesinos emigraban a la ciudad de México en los períodos agrícolas "muertos", por lo general a desempeñar ocupaciones de albañil y estibador y con frecuencia las familias recibŕan transferencias de ingresos de hombres y mujeres jóvenes que habían emigrado definitivamente al Distrito Federal.

En las regiones productoras de plantación, en especial del Golfo y del Pacífico Sur, el considerable incremento en la producción redundó en mayores oportunidades de empleo para los jornaleros; sin embargo, son las regiones donde los salarios son más bajos (en términos monetarios y reales), pues se trata de una agricultura capitalista que basa sus 
ganancias en la utilización de grandes extensiones de tierra y mano de obra abundante, la cual, por el atraso mismo de las regiones, con dificultad encuentra alternativas ocupacionales, y la migración hacia áreas urbanas o de agricultura moderna constituye una solución más lejana que para los habitantes de la parte centro del país. En estas regiones, son también frecuentes las migraciones de jornaleros de las comunidades más pobres hacia las relativamente ricas en las épocas de cosechas de caña de azúcar, café y copra.

\section{Periodo $1960-1973$}

a) Absorción de mano de obra a nivel nacional. Aun cuando no se estimaron los efectos que los cambios en los rendimientos y en el grado de mecanización tuvieron sobre el empleo durante 1940-1960, debido a la importancia que parecen haber tenido, se consideró conveniente evaluar su impacto en el período 1960-1973.

Con el objeto de conocer el monto de mano de obra utilizada en la agricultura y sus cambios entre 1960 y 1973 , se estimaron los requerimientos totales de mano de obra, para lo cual además de la superficie agrícola y la estructura productiva se consideraron el grado de mecanización y los rendimientos físicos prevalecientes. Para estos cálculos se distingue entre áreas de riego y de temporal, en atención a que entre estos dos tipos de áreas existen diferencias notables en la composición de cultivos, rendimientos y grado de mecanización. Estas distinciones se tomaron en cuenta en el caso de los cultivos del ciclo corto (a los que corresponde más del $90 \%$ de la superície cosechada), pues para los perennes sólo fue posible contar con coeficientes agregados para los principales productos. Esto permitió, además (por lo que respecta al primer tipo de cultivos), aislar la influencia de cada uno de los factores determinantes de la utilización de mano de obra.

En primer lugar se encontró que mientras de 1940 a 1960 los requerimientos totales de mano de obra se incrementaron a una tasa media anual superior a $3 \%$, en este período el aumento fue apenas del $1.4 \%$ para todos los cultivos; pero si se distingue entre los de ciclo corto y los perennes, las tasas correspondientes son 1.1 y $2.6 \%$, respectivamente, ${ }^{15}$ lo que se explica por el hecho de que la pérdida de dinamismo agrícola afectó de manera principal a los primeros, además de que las plantaciones y frutales son mucho más intensivos en mano de obra, por lo cual con menos del $10 \%$ de la superficie agrícola absorben cerca del $20 \%$ de la fuerza de trabajo agrícola total.

i) Efecto superficie. Entre 1960 y 1973, el incremento en la utilización de mano de obra en cultivos de ciclo corto, se debió de manera

15 Para el período 1940-1960, las estimaciones utilizadas no permiten distinguir entre cultivos de ciclo corto y perennes. 
Cuadro 7

INCREMENTO EN LA ABSORCIÓN DE MANO DE OBRA EN CULTIVOS DE CICLO CORTO POR FACTORES DETERMINANTES, 1960-1973

\begin{tabular}{lc}
\hline Total & $\begin{array}{c}\text { Tasa mejis anuel } \\
\text { cie increasto } 3 /\end{array}$ \\
Efecto superficio & 1.1 \\
Efecto rendimiento & 0.6 \\
Efecto mecanización & 0.5 \\
Efocto cosposicion de cultivos & -0.3 \\
\hline
\end{tabular}

a El incremento total es la suma del efecto rendimiento y el efecto superficie.

principal al aumento en la superficie agrícola; sin embargo, este efecto fue de poca magnitud como consecuencia de que entre 1965 y 1973 la superficie cosechada registró una ligera disminución (a una tasa media anual de $0.5 \%$ ), disminución registrada en las áreas de temporal mientras la superficie de riego aumentó a ritmo muy lento.

El aumento de los requerimientos de mano de obra para administración fue igualmente reducido (1.7\% anual medio), dado que está relacionado de manera directa con los aumentos en la superficie destinada a la agricultura.

El estancamiento que registra la superficie agrícola se debió de manera principal al deterioro de las relaciones de precios entre productos agrícolas y no agrícolas y a la reducida participación de la inversión agropecuaria dentro de la inversión pública federal (alrededor del 10.3\% en el período 1965-1970).

La disminución de la inversión en programas de fomento agropecua. rio dentro de la inversión pública total, significó un ritmo menor de a.umento en las superficies beneficiadas con riego, limitaciones en el número de obras dedicadas a abrir tierras al cultivo (como los desmontes) y menores alicientes para realizar inversiones privadas en la apertura de tierras de temporal por la escasez de programas de investigación y extensión en este tipo de zonas.

ii) Efecto rendimiento. La contribución de la elevación de rendimientos al aumento en la utilización de mano de obra agrícola, en el período 1960-1973 fue casi de la misma magnitud que el efecto superficie.

Después de 1965 y en particular en los últimos cuatro años, se registró una elevación en los rendimientos de la mayoría de los cultivos a un ritmo mucho menor que en los períodos precedentes. En adición, el efecto que sobre la utilización de mano de obra pueda tener una elevación en los rendimientos de los cultivos que usan de manera intensiva este factor durante la época de la cosecha, se reduce por el hecho de que este tipo de cultivos ha perdido importancia relativa dentro de la producción agrícola nacional. 
iii) Efecto composición de cultivos. Como se ha señalado, la absorción de mano de obra - al igual que el producto agrícola - se ve afectada no sólo por los cambios en la superficie agrícola y los rendimientos, sino por el cambio en la composición de cultivos y, debido a que los cultivos que registraron mayor dinamismo desde principios del decenio de los sesentas son poco intensivos en el uso de mano de obra (sorgo,

\section{Gráfica 1}

ÍNDICE DE CAMBIOS ACUMULATIVOS DEL PRODUCTO AGRícolA $Y$ DE LOS REQUERIMIENTOS DE MANO DE OBRA, DE 1960 A 1973 a

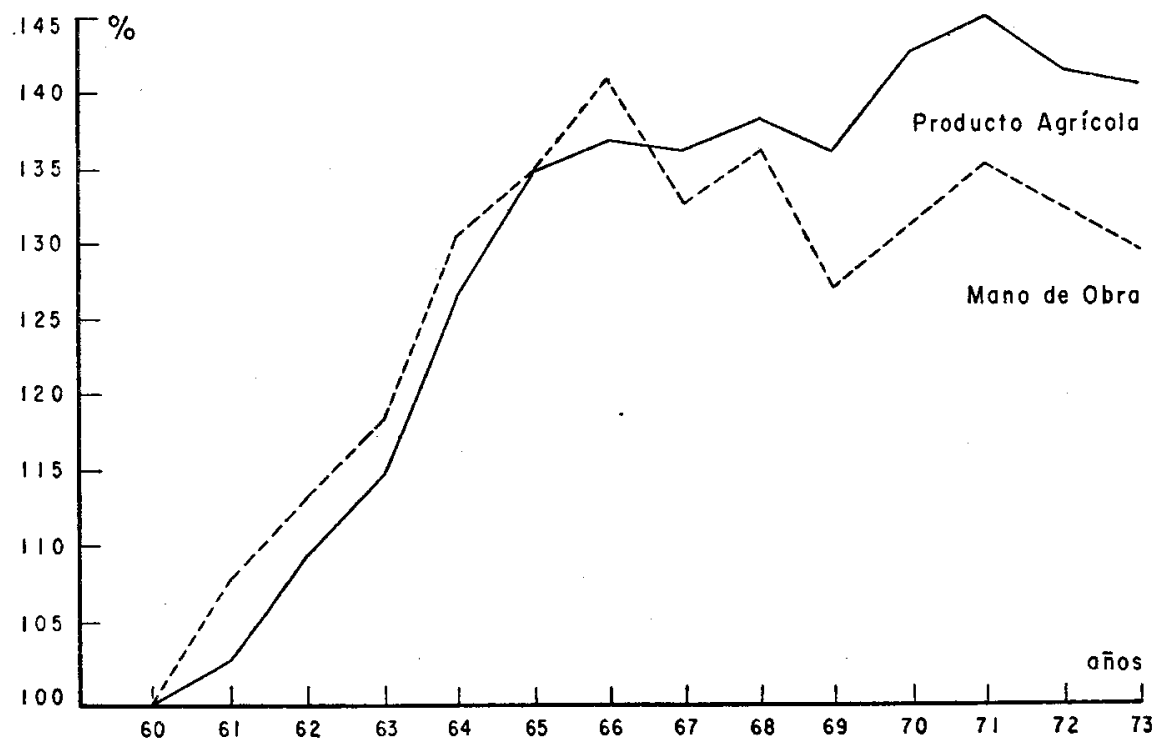

Fuente: Producto agrícola: Banco de México, Informe Anual; requerimientos de mano de obra: Datos de la Comisión Nacional Coordinadora del Sector Agropecuario.

a Los cambios en los requerimientos de mano de obra corresponden únicamente a cultivos de ciclo corto y no reflejan el efecto negativo de la mecanización.

cártamo y soya), el cambio en la composición de cultivos tuvo un efecto empleo de signo negativo.

Como en general los cultivos más intensivos en el uso de mano de obra son precisamente los de mayor rendimiento monetario por hectárea, los requerimientos de dicho factor de la producción y el producto agrícola varían en el mismo sentido, como se aprecia en la gráfica 1.

En el período considerado, el cambio en la composición de cultivos provocó una disminución de $0.6 \%$ anual en la utilización de mano de obra, efecto que superó de manera notable el efecto negativo de la me- 
canización (de $0.3 \%$ anual medio), e igualó en magnitud al efecto positivo que resultó del aumento en la superficie cosechada. Es decir, dados los cambios en los otros tres factores (superficie, rendimientos y grado de mecanización), si la composición de cultivos de 1960 se hubiera mantenido en 1973, los requerimientos de mano de obra hubieran aumentado a una tasa media anual de $1.7 \%$

El efecto negativo del cambio en la composición de cultivos, se refleja en una disminución en la media de días-hombre por hectárea de 1960 a 1973, lo cual ocurrió no sólo en el caso de los cultivos de ciclo corto, sino inclusive en los perennes, debido a que dentro de estos últimos, los cultivos cuya superficie registró los mayores aumentos fueron los frutales, que son relativamente menos intensivos en uso de mano de obra que las plantaciones.

iv) Efecto mecanización. El incremento en las necesidades de mano de obra ha sido menor de lo que muestra la gráfica 1, pues la sustitución de mano de obra por maquinaria, derivada de la creciente mecanización, ha disminuido aún más las posibilidades de empleo agrícola.

De acuerdo con la información disponible al respecto, el acelerado proceso de mecanización característico de los años cincuentas se mantuvo durante el decenio de los sesentas y parece no revertirse en los últimos años. Esto contradice la idea generalizada de considerar mecanización como sinónimo de desarrollo agrícola, ya que en este período el comportamiento del producto agrícola ha ido en sentido inverso a la "modernización".

\section{Cuadro 8}

SUPERFICIE DE LABOR POR GRADO DE MECANIZACIÓN (Porcientos)

\begin{tabular}{lccc}
\hline & Mecanizada & $\begin{array}{c}\text { Parcialesnte } \\
\text { mecanizada }\end{array}$ & Mooanizada \\
\hline $\begin{array}{c}\text { Superficie total } \\
1960\end{array}$ & 8.2 & 20.6 & 71.2 \\
1970 & 21.5 & 16.1 & 62.4 \\
Superficie de riego & & & \\
1963-1964 & 41.8 & 39.9 & 18.3 \\
$1970-1971$ & 52.7 & 38.7 & 8.6 \\
$1972-1973$ & 56.7 & 35.3 & 8.0 \\
\hline
\end{tabular}

Fuente: Para la superficie total: Censos Agrícolas de 1960 y 1970; y para superficie de riego: Secretaría de Recursos Hidráulicos, Mecanización de los Distritos de Riego, 1972.

El cuadro 8 permite tener una idea del proceso de mecanización durante el período $1960-1973$.

Si se hubiera mantenido hasta 1973 el grado de mecanización existente en 1960 , los requerimientos de mano de obra agrícola en cultivos de ciclo corto hubieran crecido a una tasa media anual de $1.4 \%$ (en vez de $1.1 \%$ ), lo cual significa que la mecanización provocó una reducción 
Cuadro 9

SUPERFICIE Y ABSORCIÓN DE MANO DE OBRA EN CULTIVOS DE CICLO CORTO, 1960 Y 1973

\begin{tabular}{|c|c|c|c|c|c|}
\hline \multirow[b]{2}{*}{1960} & \multicolumn{2}{|c|}{ Superficie cosechada } & \multicolumn{3}{|c|}{ Requerimientos de mano de obra } \\
\hline & Hectareas & $\mathscr{0}$ & $\begin{array}{c}\text { Dfas-hombre } \\
\text { al año a }\end{array}$ & $\%$ & $\begin{array}{l}\text { Difasmombre } \\
\text { por hectárea }\end{array}$ \\
\hline Total & 13447 & 100.0 & $54 i 376$ & 100.0 & 40.26 \\
\hline A jo & 7 & 0.1 & 682 & 0.1 & 97.43 \\
\hline $\begin{array}{l}\text { Alfalfa achica } \\
\text { lada }\end{array}$ & 43 & 0.3 & 1304 & 0.2 & 30.33 \\
\hline GIgodsn & 509 & 3.8 & 40516 & 7.5 & 79.60 \\
\hline Alfalfa verde & 177 & 1.3 & 8273 & 1.5 & 46.74 \\
\hline Arroz & 164. & 1.2 & 11961 & 2.2 & 72.93 \\
\hline Avena & 131 & 1.0 & 2033 & 0.4 & 15.52 \\
\hline Caña de azucar & 483 & 3.6 & $40 \quad 096$ & 7.4 & 82.14 \\
\hline Camote & 10 & 0.1 & 544 & 0.1 & 54.40 \\
\hline Cártamo & 196 & 1.5 & 3379 & 0.6 & 17.24 \\
\hline Cacahuate & 45 & 0.3 & 3199 & 0.6 & 71.09 \\
\hline Cebolla & 25 & 0.2 & 2647 & 0.5 & 105.88 \\
\hline Cebada erano & 230 & 1.7 & 3480 & 0.6 & 15.13 \\
\hline Chale seco & 26 & 0.2 & 2509 & 0.5 & 98.81 \\
\hline Chile verde & $6:$ & 0.5 & 8936 & 1.7 & $146 \quad 49$ \\
\hline Fresa & 7 & 0.1 & 493 & 0.1 & 70.43 \\
\hline Frajol & 629 & 12.1 & 53815 & 9.9 & 33.04 \\
\hline Garbanzo & 221 & 1.6 & 7794 & 1.4 & 35.27 \\
\hline Haba & 58 & 0.4 & 1935 & 0.4 & 33.36 \\
\hline J 2 tomate & 71 & 0.5 & $10 \quad 020$ & 1.9 & 141.13 \\
\hline sjonjol: & 258 & 1.9 & 10420 & 1.9 & 40.39 \\
\hline Lunaza & 8 & 0.1 & 53 & $-E$ & 6.63 \\
\hline Mafz & 6799 & 10.5 & 255256 & 47.3 & 37.54 \\
\hline Melon & 18 & 0.1 & 2223 & 0.4 & 123.50 \\
\hline Papa & 54 & 0.4 & 3020 & 0.6 & 55.93 \\
\hline Pepino & 7 & 0.1 & 661 & 0.1 & 94.43 \\
\hline Piña & 7 & 0.1 & 1252 & 0.2 & 178.86 \\
\hline Sandía & 29 & 0.2 & 3491 & 0.6 & 120.38 \\
\hline Sorgo & 1146 & 8.5 & 39598 & 7.3 & 34.55 \\
\hline Soya & 283 & 2.1 & 8612 & 1.6 & 30.43 \\
\hline Tabaco & 39 & 0.3 & 4247 & 0.3 & 105.90 \\
\hline Trigo & 702 & 5.2 & 8377 & 1.6 & 12.65 \\
\hline
\end{tabular}

en la absorción de mano de obra agrícola nacional de $0.3 \%$ anual medio, contrarrestando de manera parcial los efectos del aumento de la superficie agrícola y de los rendimientos.

De esta manera en las áreas de riego, donde los factores que tienen un efecto positivo sobre el empleo (superficie agrícola y rendimientos) son más dinámicos, la sustitución de mano de obra por maquinaria ha impedido que tal dinamismo se traduzca en mayores oportunidades de 
Cuadro 9 (Continuación)

\begin{tabular}{|c|c|c|c|c|c|}
\hline \multirow[b]{2}{*}{1973} & \multicolumn{2}{|c|}{ Superficie cooechada } & \multicolumn{3}{|c|}{ Requerimientes de mano de obra } \\
\hline & Hectareas & $\bar{t}$ & $\begin{array}{l}\text { Dfas-hombre } \\
\text { al año a }\end{array}$ & $\%$ & $\begin{array}{l}\text { Dfas-hombre } \\
\text { por hectárea }\end{array}$ \\
\hline Total & 11059 & 100.0 & 468879 & 100.0 & 42.40 \\
\hline Ajo & 5 & $-\underline{b}$ & 533 & 0.1 & 106.60 \\
\hline $\begin{array}{l}\text { Alfalfa achjca } \\
\text { lada }\end{array}$ & 30 & 0.3 & 1128 & 0.2 & 37.60 \\
\hline AIgodón & 815 & 7.4 & 58730 & 12.5 & 72.06 \\
\hline Alfalfa varde & 92 & 0.8 & 6347 & 1.4 & 69.53 \\
\hline Arroz & 139 & 1.2 & 9859 & 2.1 & 70.93 \\
\hline Avena & 87 & 0.8 & 1413 & 0.3 & 16.30 \\
\hline Caña de azocar & 336 & 3.0 & 25733 & 5.5 & 76.59 \\
\hline Canote & 15 & u. 1 & 575 & 0.1 & 38.33 \\
\hline Cofrtano & 29 & 0.3 & 428 & 0.1 & 14.75 \\
\hline Cacahuate & 74 & 0.7 & 5308 & 1.1 & 71.73 \\
\hline Cebolla & 15 & 0.1 & $\begin{array}{ll}1 & 127\end{array}$ & 0.2 & 75.12 \\
\hline Cebada grano & 238 & 2.2 & 3558 & 0.8 & $14 \cdot 95$ \\
\hline Chile seco & 24 & 0.2 & 2292 & 0.5 & 95.50 \\
\hline Chile verde & 33 & 0.3 & 3335 & 0.8 & 116.21 \\
\hline Fresa & 5 & - b) & 348 & 0.1 & 69.60 \\
\hline Frijol & 1451 & 13.1 & 50720 & 10.8 & 34.96 \\
\hline Garbanzo & 150 & 1.4 & 5571 & 1.2 & 36.74 \\
\hline Haba & 38 & 0.3 & 1390 & 0.3 & 36.32 \\
\hline Jitomate & 63 & 0.6 & 6748 & 1.4 & 107.11 \\
\hline AjonjoIL & 203 & 1.8 & 8895 & 1.9 & 43.32 \\
\hline Linaza & 23 & 0.2 & 297 & 0.5 & 12.91 \\
\hline Malz & 6058 & 34.8 & 247811 & 52.9 & 40.91 \\
\hline Ne16n & 15 & 0.1 & 1475 & 0.3 & 98.00 \\
\hline Papa & $\triangle 6$ & 0.4 & 2144 & 0.5 & 46.61 \\
\hline Pepino & 0.3 & $-\mathfrak{b}$ & 24 & $-E$ & 80.00 \\
\hline Fiña & 8 & 0.1 & 1073 & 0.2 & 134.13 \\
\hline Sandia & 21 & 0.2 & 2225 & 0.5 & 105.95 \\
\hline Sorgo & 113 & 1.0 & 3 od I & 0.8 & 32.58 \\
\hline Soya & 9 & 0.1 & 220 & $-y$ & 24.44 \\
\hline Tabaco & 53 & 0.5 & 5732 & 1.2 & 143.15 \\
\hline Trigo & 871 & 7.9 & 9729 & 2.1 & $11 \cdot 17$ \\
\hline
\end{tabular}

a Miles.

b No significativo.

empleo para los campesinos sin tierra, que son quienes llevan a cabo la producción en este tipo de unidades productoras.

Como la utilización de maquinaria lleva implícito el empleo de mano de obra calificada para su operación, el acelerado proceso de mecanización provocó que los requerimientos de este tipo de mano de obra aumentaran un $65 \%$ durante el período analizado; sin embargo, en términos absolutos, este incremento fue sólo de 6.1 millones de días-hombre, 
mientras el desplazamiento de mano de obra "no calificada" fruto de la mecanización, significó 21.2 millones de días-hombre.

v) Cambios en la utilización de mano de obra por cultivos. En los cuadros 9 y 10 se puede observar cómo en general los cultivos más intensivos en el uso de mano de obra han disminuido su importancia relativa como generadores de empleo al reducirse su importancia en la superficie cosechada total. A partir de las variaciones en el número de días-hombre por hectárea para cada cultivo entre 1960 y 1973, se obser. va que en general los granos han reducido su intensidad en el uso del mencionado factor, lo cual es explicable en función de la creciente mecanización. Lo contrario ha ocurrido con el algodón, las hortalizas y los

Cuadro 10

SUPERFICIE Y ABSORCIÓN DE MANO DE OBRA EN CULTIVOS PERENNES, 1960 Y 1973

\begin{tabular}{|c|c|c|c|c|c|}
\hline & \multicolumn{2}{|c|}{ Superficie cosechada } & \multicolumn{3}{|c|}{ Reguerimientos de mano de obra } \\
\hline & tectáreas & 76 & $\begin{array}{l}\text { Dias-hombre } \\
\text { al año a }\end{array}$ & 若 & $\begin{array}{l}\text { Dias-hombre } \\
\text { por hectáreas }\end{array}$ \\
\hline \multicolumn{6}{|l|}{1960} \\
\hline Total & 840329 & 100.00 & $902 \quad 431$ & 100.00 & 121.9 \\
\hline Manzana & 6659 & 0.79 & 599 & - 0.59 & 78.0 \\
\hline Kango & 8302 & 0.99 & 1058 & 1.03 & 127.5 \\
\hline Agracate & 8539 & 1.02 & 925 & 0.90 & 108.3 \\
\hline Vid & 11334 & 1.35 & 3104 & 3.03 & 273.8 \\
\hline Naranja & 69691 & 8.29 & 3659 & 3.57 & 52.5 \\
\hline Cafs & 298935 & 35.57 & 41313 & 40.33 & 138.2 \\
\hline Pletano & 53263 & 6.34 & 5092 & 4.97 & 95.6 \\
\hline Otros & 383606 & 45.65 & 46762 & 45.65 & 121.9 \\
\hline \multicolumn{6}{|l|}{1973} \\
\hline Total & 1279088 & 100.00 & 143345 & 100.00 & 112.1 \\
\hline Manzana & 30615 & 2.39 & 1959 & 1.37 & 64.0 \\
\hline Kango & 29398 & 2.30 & 2469 & 1.72 & 84.0 \\
\hline Aguacate & 28792 & 2.25 & 2534 & 1.77 & 88.0 \\
\hline Vid & 19361 & 1.51 & 5856 & $4 \cdot 11$ & 304.0 \\
\hline Naranja & 155686 & $\$ 2.17$ & 8173 & 5.70 & 52.5 \\
\hline Cafes & $370 \quad 126$ & 28.95 & 51151 & 35.68 & 138.2 \\
\hline Pistano & 68356 & 5.34 & 6535 & 4.56 & 95.6 \\
\hline Otros & 576754 & 45.09 & 64637 & 45.09 & 102.1 \\
\hline
\end{tabular}

a Miles.

frutales, pues el hecho de que sus mayores requerimientos de mano de obra se den en la cosecha, indujo a que el efecto de la elevación en los rendimientos superara el efecto negativo de la mecanización; no obstante, esto agrava el problema de estacionalidad.

Por lo que respecta a las oleaginosas, las tradicionales (ajonjolí, linaza y cacahuate), han disminuido su intensidad, ya que se concentraron cada vez más en áreas de riego, donde el proceso de mecanización es 
más acentuado; en tanto las oleaginosas de fomento más reciente (soya y cártamo), lo mismo que el sorgo, se han vuelto más intensivas en el uso del factor que nos ocupa puesto que en $1960 \mathrm{su}$ explotación se llevaba a cabo casi en exclusiva en áreas de riego y en la actualidad se están extendiendo a zonas de temporal (con menor mecanización).

Respecto a los cultivos perennes, a partir de las estimaciones realizadas no es posible saber qué ha ocurrido con la intensidad en el uso de mano de obra de cada uno de ellos en particular, pues para las plantaciones se usaron coeficientes fijos para ambas fechas y para los frutales se consideraron variaciones en los coeficientes, sólo en función del aumento en rendimientos. Sin embargo, lo más probable es que dicha intensidad no haya cambiado de manera sustancial por tratarse en general de cultivos propios de zonas tropicales (en especial las plantaciones), en cuya explotación se siguen utilizando métodos más o menos tradicionales. Por lo tanto, los aumentos en rendimientos crecen de manera mucho más lenta que en el caso de los cultivos de ciclo corto y el proceso de mecanización es menos acelerado.

vi) Utilización de mano de obra en áreas de riego y de temporal. Si se distingue entre áreas de riego y de temporal, ${ }^{16}$ el incremento en los

\section{Cuadro 11}

ABSORCIÓN DE MANO DE OBRA EN CULTIVOS DE CICLO CORTO SEGÚN CALIDAD DE LA TIERRA, 1960 Y 1973 (Miles de dias-hombre)

\begin{tabular}{|c|c|c|c|c|c|c|}
\hline & \multicolumn{3}{|c|}{1950} & \multicolumn{3}{|c|}{1973} \\
\hline & Total & $q$ & $\begin{array}{c}\text { Por hec } \\
\text { t sraa }\end{array}$ & Total & $\$$ & $\begin{array}{l}\text { Por hee } \\
\text { tarea }\end{array}$ \\
\hline Total & 468.879 & 100.0 & 42.40 & 541376 & 100.0 & 40.26 \\
\hline Riego & 107856 & 23.0 & 53.68 & 110702 & 20.4 & 46.55 \\
\hline Temporal & 361023 & 77.0 & 39.88 & 430674 & 79.6 & 38.90 \\
\hline
\end{tabular}

requerimientos de mano de obra fue mucho más reducido en las primeras, de tal manera que su contribución a la generación de nuevo empleo resultó definitivamente insignificante (véase el cuadro 11).

La falta de dinamismo de las tierras irrigadas como generadoras de empleo se debió a que los efectos negativos de la mecanización y en especial el cambio en la composición de cultivos, registraron aquí una mayor incidencia que en las zonas de temporal. Esto se refleja en una también mayor reducción de la intensidad en el uso de mano de obra: mientras en 1960 una hectárea cosechada de riego generaba 13.80 jornadas más de empleo que una de temporal, en 1973 la diferencia se redujo a 7.65 jornadas. ${ }^{17}$

16 De nuevo nos referimos sólo a cultivos de ciclo corto.

17 Nótese que se está hablando de días-hombre por hectárea cosechada, ya que 
vii) Estacionalidad. Con objeto de ilustrar los cambios en la utilización de mano de obra durante el período 1960-1973 y la estacionalidad de la ocupación agrícola, en la gráfica 2 se muestran los requerimientos de mano de obra en esos dos años y su distribución mensual; cada una de estas curvas es una agregación de la mano de obra requerida mensualmente en la producción de los distintos cultivos que se obtuvieron tanto en áreas de riego como de temporal, de acuerdo con sus fechas de siembra y de cosecha. En las zonas de temporal, la estacionalidad es aún mucho más marcada de lo que se muestra en la gráfica, en virtud de que por lo general se obtiene sólo un cultivo al año.

Se tiene entonces que para el país en su conjunto, las necesidades de mano de obra se concentran en los meses correspondientes a las épocas de cosecha de los dos ciclos agrícolas predominantes y que en los meses posteriores a la cosecha dichas necesidades se reducen de manera drástica. Así, en agosto, que es el mes de máxima ocupación debido a que se obtienen la mayor parte de las cosechas del ciclo primavera-verano, los requerimientos de mano de obra son tres veces mayores que en septiembre.

\section{b) Absorción de mano de obra por grupos de tenencia de la tierra}

En cuanto a los distintos grupos de tenencia de la tierra, durante este lapso el pincipal incremento en la absorción de mano de obra correspondió a los ejidos, como consecuencia de que fue en este grupo donde se dieron los mayores aumentos de la superficie agrícola, a la vez que el efecto negativo del cambio en la sustitución de cultivos fue menor que en el caso de los predios privados mayores de cinco hectáreas. En estos últimos, la cantidad de mano de obra absorbida permanece constante durante el período analizado, lo cual parece indicar que los efectos negativos de la mecanización y el cambio en la composición de cultivos, contrarrestaron los efectos del incremento en superficie y en los rendimientos.

Por lo que se refiere a los predios privados de cinco hectáreas o menos, los requerimientos totales de mano de obra disminuyeron debido a que hubo una reducción en el número de los mismos y de la superficie correspondiente, tendencia que se manifestaba desde 1950 y que puede interpretarse como prueba de que el minifundio no es una unidad de producción redituable. ${ }^{18}$

por hectárea física los requerimientos de mano de obra en áreas de riego son aún mayores debido al cultivo doble.

18 Los cálculos de requerimientos de mano de obra por grupos de tenencia de la tierra se basan en información de los censos agrícolas de 1960 y 1970 , la cual induce a sobreestimar el incremento ocurrido en el sector ejidal y a subestimarlo en los predios privados mayores de 5 hectáreas. Esto se debe a que, por una parte, en 1960 las comunidades agrarias se registraron junto con los predios privados y en 1970 se sumaron a los ejidos y por otra parte, la superficie agrícola de 1960, en especial la de predios privados, parece estar sobreestimada. Asimismo, la disminución en el número de predios privados de 5 hectáreas o menos y de su superficie 
Gráfica 2

ESTIMACIONES DE EMPLEO ESTACIONAL EN CULTIVOS DE CICLO CORTO Y PERENNES, 1960 Y 1973

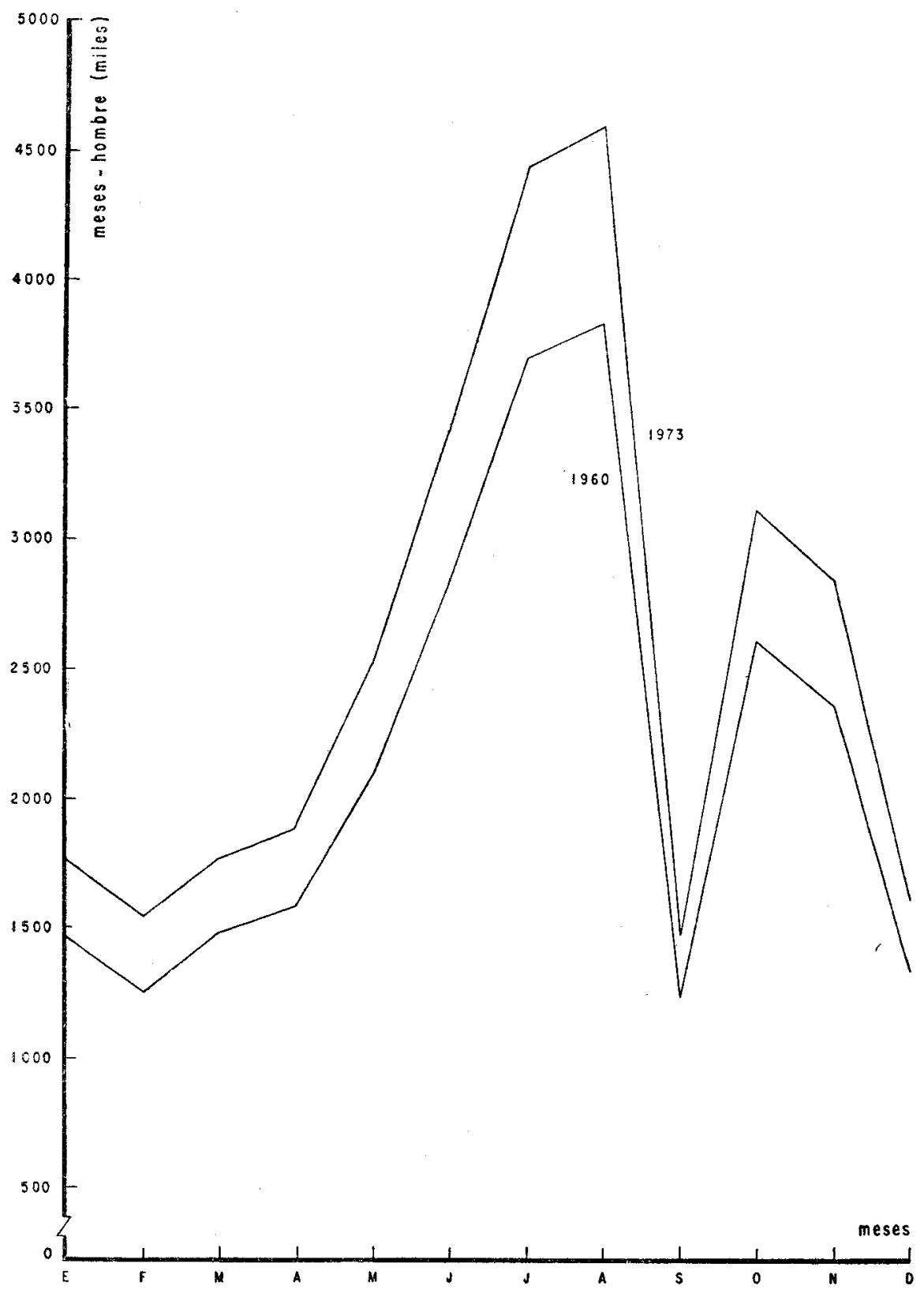




\section{Cuadro 12}

ABSORCIÓN DE MANO DE OBRA EN LA ACTIVIDAD AGRÍCOLA, 1960 y 1973

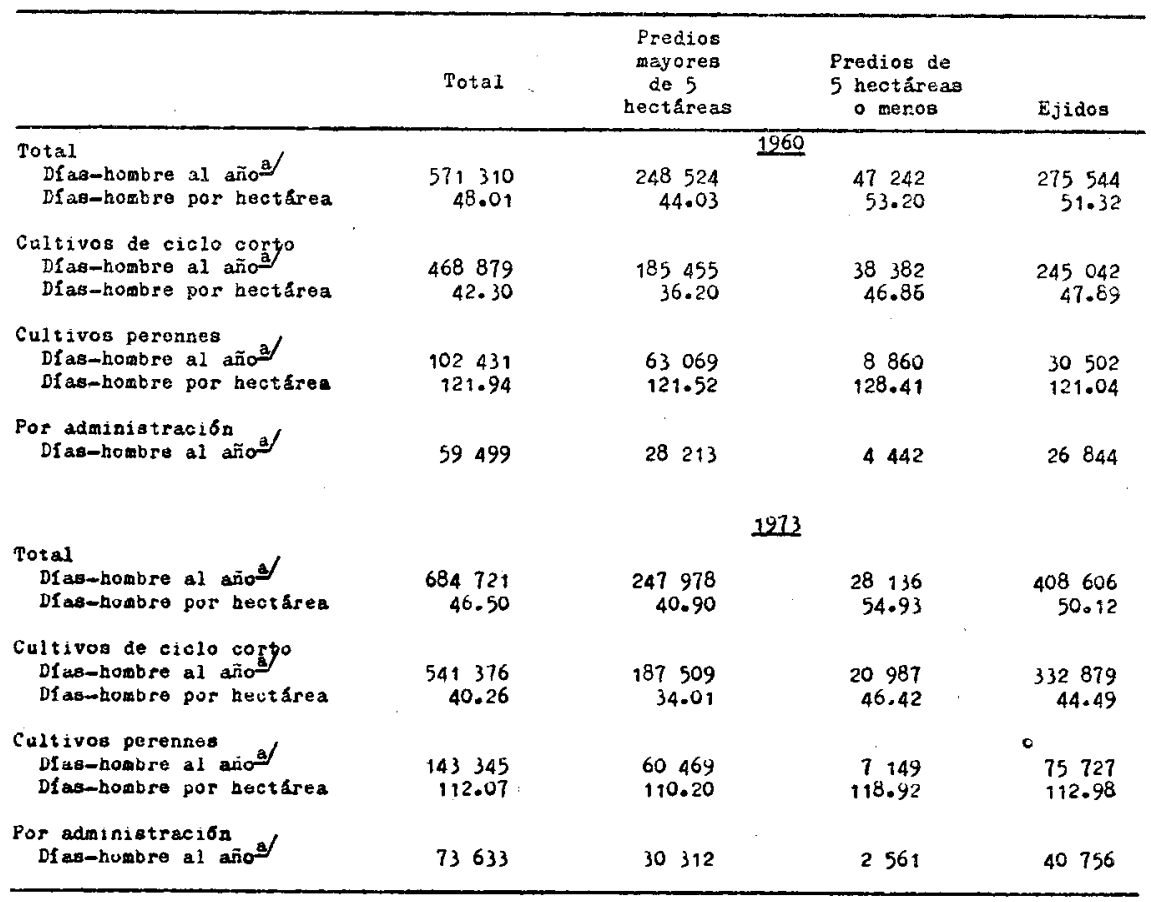

a Miles.

Es interesante observar que la intensidad en el uso de mano de obra es mayor en los predios pequeños que en los otros dos grupos, y a su vez, es mayor en los ejidos que en los predios privados mayores de cinco hectáreas, como lo demuestran los coeficientes medios de días-hombre utilizados por hectárea para cada uno de los grupos en las dos fechas consideradas (véase el cuadro 12 ).

Esta diferencia es atribuible a que el grado de mecanización es considerablemente mayor en los predios grandes, lo que contrarresta la ventaja

y la consecuente reducción en la mano de obra parecen estar sobreestimadas en virtud de que entre ambos censos el predio puede haberse captado de diferente manera. En 1970 se hace la aclaración de que debe entenderse como predio la unidad productora, la cual puede estar formada por una o varias porciones de terreno (es decir un solo predio o varios predios) siempre que se exploten bajo una misma administración y con los mismos instrumentos de trabajo (maquinaria, yunta, etc.). En el de 1960, aun cuando la definición de predio era la misma, no se dio la instrucción precisa al personal encargado del levantamiento, por lo que es probable que las unidades productoras formadas por varias porciones de terreno se hayan captado de manera fraccionada. 
para absorber mano de obra que les proporciona el concentrar la mayor parte del agua para riego.

La diferencia en el grado de intensidad en el uso de mano de obra entre grupos, en la realidad debe ser inferior a lo que reflejan las estimaciones mencionadas debido a que, con fines de simplificación, se hizo el supuesto de rendimientos iguales entre grupos, cuando en efecto éstos son mayores en los predios de más de cinco hectáreas, donde el uso de fertilizantes, insecticidas, semillas mejoradas y en general los métodos de cultivo más avanzados son más frecuentes.

De acuerdo con las estimaciones para 1940 y 1960, la intensidad de mano de obra está en favor de los predios privados grandes debido a que dichas estimaciones se basan en coeficientes fijos entre grupos de tenencia para cada cultivo y por lo tanto sólo reflejan los efectos superficie y composición de cultivos y no las diferencias en el grado de mecanización. ${ }^{19}$

\section{c) Absorción de mano de obra por regiones}

Durante el período considerado, el mayor incremento en el uso de mano de obra se registró en la parte central del país, en virtud de que fue allí donde la superficie agrícolả registró la mayor expansión; la elevación de los rendimientos físicos de los cultivos fueron en general importantes; el grado de mecanización es de los más bajos del país (salvo en el Estado de Guanajuato) y el cambio en la composición de cultivos no tuvo efectos negativos de consideración sobre el empleo (como ocurrió a nivel nacional). Sin embargo, este incremento en las necesidades de fuerza de trabajo agrícola resulta insignificante a la luz de la presión mano de obra-tierra que existe, por tratarse de la región de mayor densidad de población de México.

En el Noroeste, a pesar de ser una de las regiones donde la superficie agrícola creció más rápidamente, la absorción de mano de obra se vio restringida como resultado de la sustitución de maíz y sobre todo de algodón a favor de sorgo, soya y cártamo, cultivos poco intensivos en el uso de mano de obra, en especial cuando se utiliza tracción mecánica como sucede en esta región. Después de 1973, la superficie algodonera se ha reducido de manera aún más drástica, con lo cual se ha eliminado la fuente de empleo (y de ingreso) de miles de jornaleros. Eran tradicionales las migraciones de personas que iban desde el sur y centro de la República a la pizca de algodón al Noroeste, donde debido al escalonamiento de las cosechas podían encontrar ocupación durante por lo menos tres meses del año desplazándose desde el norte de Sinaloa hasta Mexicali; sin embargo, dada la superficie que actualmente se destina al cultivo de esta

19 En un estudio sobre empleo rural realizado por PREALC en El Salvador se encontró que la intensidad en el uso de mano de obra por hectárea está en relación inversa al tamaño del predio. 
malvácea, para cubrir los requerimientos de mano de obra durante la cosecha basta con la mano de obra local, según información de los productores mismos.

La sustitución de algodón por cultivos menos intensivos en mano de cbra, también ha reducido de manera considerable la absorción de este factor en los estados del Norte y noreste, lo cual se ha visto agravado por el lento ritmo al que ha crecido la superficie agrícola.

La reducción de oportunidades ocupacionales para los jornaleros agrícolas resultante del cambio en la estructura productiva con el que adquieren preponderancia los cultivos poco intensivos en mano de obra y que tuvo lugar de 1960 a 1973 en todas las entidades del norte (en las que predomina la agricultura capitalista), se ha agudizado por el hecho de que en estas regiones en especial, el acelerado proceso de mecanización de las labores agrícolas continúa.

En el resto del país, los aumentos en los requerimientos de mano de obra fueron de poca magnitud y pueden atribuirse de manera principal al leve aumento de la superficie agrícola, pues los otros factores determinantes mostraron poco dinamismo.

\section{CONSECUENCIAS DEL ESTANCAMIENTO AGRÍCOLA PARA LA POBLACIÓN TRABAJADORA}

De acuerdo con el Censo de Población (véase el cuadro 6), durante el decenio de los sesentas, en que se inicia el estancamiento agrícola, la PEA dedicada principalmente a las actividades agropecuarias mantuvo el lento ritmo de crecimiento registrado durante el decenio anterior $(0.5 \%$ anual niedio). Las personas que se incorporan a la fuerza de trabajo de las áreas rurales, se han visto precisadas cada vez más a buscar su fuente de sustento fuera de la agricultura, sea como trabajadores asalariados o por cuenta propia.

Según los censos agrícolas de 1960 y 1970 , el número de personas dedicadas a la agricultura ( 7.8 millones), permanece constante durante ese lapso. Esto puede atribuirse al hecho de que los datos de personal ocupado a que se refiere el censo de 1960 , son los registrados el día en que se llenó el cuestionario, que quedó comprendido en el lapso de mayo a junio, de actividad agrícola relativamente intensa en la mayor parte de las regiones del país; mientras los datos de 1970 se refieren al personal ocupado durante la semana anterior al levantamiento del censo, que se llevó a cabo durante febrero y marzo, meses de escasa actividad agrícola.

Sin embargo, de acuerdo con ambas fuentes de información, el número de jornaleros del campo aumentó de manera considerable, como se aprecia en el cuadro 13. Este incremento puede atribuirse a la falta de oportunidades ocupacionales en el resto de los sectores económicos y al hecho de que para los hijos de ejidatarios y pequeños propietarios privados, es cada vez más difícil obtener un pedazo de tierra donde sembrar. 
Cuadro 13

Población ECONÓMICAMENTE ACtIVA (PEA) EN ACTIVIdAdes AgRopecuarias SEGÚN POSICIÓN EN LA OCUPACIÓN, 1960 Y $1970^{a}$ (Miles de personas)

\begin{tabular}{|c|c|c|c|c|}
\hline & \multicolumn{2}{|c|}{ Censo de pablacion } & \multicolumn{2}{|c|}{$\begin{array}{c}\text { Censo agrfcola, ganadero } \\
\text { Yejidal }\end{array}$} \\
\hline & 1960 b & 1970 & $\overline{1960}$ & 1970 \\
\hline Total & 5048 & 5293 & 7862 & 7837 \\
\hline $\begin{array}{l}\text { Productor } y \text { sus } \\
\text { faniliares }\end{array}$ & 2844 & 2741 & 6087 & 5302 \\
\hline Asalariados & 2204 & 2552 & 1775 & 2535 \\
\hline
\end{tabular}

Fuente: Censa Agrícola, Ganadero y Ejidal, Resumen General, 1960-1970; Oscar Altimir, "La medición de la población económicamente activa de México, 19501970", Demografía y Economía, Núm. 22, El Colegio de México, 1974; y Censo de Población, Resumen General, 1970.

a Las diferencias entre ambos censos corresponden principalmente al renglón de trabajadores familiares no remunerados, y se deben en primer lugar a los distintos criterios de captación utilizados: el Censo de Población establece límites de edad y de tiempo trabajado, no así el Censo Agrícola. Otra fuente importante de discrepancia es el hecho de que los períodos de referencia son también distintos. El cambio en los criterios para captar la PEA y los cambios de período de referencias entre los censos de población de 1960 y 1970 , resta validez a la comparación que se haga de estas cifras; algo similar ocurre con los censos agrícolas de esos mismos años. Sin embargo, a partir de ambas fuentes es posible por lo menos a grandes rasgos conocer la tendencia de la estructura ocupacional.

b Consideradas las correcciones que hizo Oscar Altimir a la PEA dedicada a actividades agropecuarias que reportó el censo de población.

De 1960 a 1970, la participación de los jornales en el gasto corriente total de los productores agrícolas, aumentó de 28 a $33 \%$, según el censo agrícola. Esto se debió a un incremento en la utilización de mano de obra asalariada en las áreas menos mecanizadas, en especial en las zonas de plantación de los estados del Golfo y del Pacífico Centro, pues en los estados en donde han tenido lugar un acelerado proceso de mecanización y una sustitución de cultivos intensivos en mano de obra por cultivos poco intensivos en este factor (en particular los del norte del país), la participación de los jornales en el gasto agrícola ha disminuido como resultado de la reducción en la mano de obra utilizada.

Por lo que se refiere a los productores que trabajan su propia tierra (productores y sus familiares), éstos no sólo han perdido importancia relativa dentro de la PEA dedicada a la agricultura, sino que disminuyeron en términos absolutos durante el decenio de los sesentas, pese a la creación de nuevas parcelas ejidales. Tal disminución puede atribuirse al hecho de que en la mayor parte de las unidades agrícolas de tipo familiar (ejidales y privadas), la escasez de recursos productivos les impide obtener ingresos suficientes para cubrir sus necesidades y utilizar productiva- 
MUNICIPIOS URBANOS DE MIGRACIÓN, 1970

\begin{tabular}{|c|c|c|c|c|c|c|c|c|}
\hline & \multirow[b]{2}{*}{ Total } & \multicolumn{2}{|c|}{ Hasta 2 años } & \multicolumn{2}{|c|}{ De 3 a 5 años } & \multicolumn{2}{|c|}{ De 6 a 10 años } & \multirow[b]{2}{*}{$\begin{array}{l}\text { De } 11 \text { y } \\
\text { mâs años }\end{array}$} \\
\hline & & Personas & : & Personas & 若 & Personas & $\not$ & \\
\hline $\begin{array}{l}\text { Baja California Norte } \\
\text { Ensenada } \\
\text { Mexicali } \\
\text { Tecate } \\
\text { Tijuana }\end{array}$ & $\begin{array}{rl}23 & 448 \\
57 & 239 \\
4 & 298 \\
106 & 908\end{array}$ & $\begin{array}{rl}9 & 518 \\
17 & 461 \\
1 & 741 \\
41 & 004\end{array}$ & $\begin{array}{l}40.59 \\
30.51 \\
40.51 \\
38.35\end{array}$ & $\begin{aligned} 6702 \\
14.759 \\
1786 \\
28784\end{aligned}$ & $\begin{array}{l}28.58 \\
25.78 \\
27.59 \\
26.92\end{array}$ & $\begin{aligned} 72228 \\
25019 \\
1371 \\
37120\end{aligned}$ & $\begin{array}{l}30.83 \\
43.71 \\
3.90 \\
34.72\end{array}$ & $\begin{array}{r}17765 \\
78635 \\
2500 \\
54932\end{array}$ \\
\hline $\begin{array}{l}\text { Chihuahua } \\
\text { Ascencion } \\
\text { Janos } \\
\text { Juárez }\end{array}$ & $\begin{array}{r}612 \\
157 \\
\text { So } 527\end{array}$ & $\begin{array}{r}258 \\
38 \\
15683\end{array}$ & $\begin{array}{l}42.16 \\
24.20 \\
31.04\end{array}$ & $\begin{array}{r}152 \\
52 \\
12 \quad 345\end{array}$ & $\begin{array}{l}24.84 \\
33.12 \\
24.43\end{array}$ & $\begin{array}{r}202 \\
67 \\
22 \quad 499\end{array}$ & $\begin{array}{l}33.00 \\
42.69 \\
44.53\end{array}$ & $\begin{array}{r}378 \\
319 \\
52977\end{array}$ \\
\hline $\begin{array}{l}\text { Querrero } \\
\text { Acapuico }\end{array}$ & 15137 & 6127 & 40.48 & 4088 & 27.01 & 4922 & 32.51 & 9875 \\
\hline $\begin{array}{l}\text { Jaliseo } \\
\text { Guadialajara } \\
\text { Tlaquepaque } \\
\text { Tonals } \\
\text { Zapopan } \\
\text { Puerto Vallarta }\end{array}$ & $\begin{array}{rl}160 & 939 \\
8230 \\
929 \\
18 \quad 655 \\
4359\end{array}$ & $\begin{array}{rl}69 & 528 \\
3 & 656 \\
464 \\
8 & 113 \\
2 & 468\end{array}$ & $\begin{array}{l}43.20 \\
44.42 \\
49.95 \\
43.49 \\
56.62\end{array}$ & $\begin{array}{rl}40 & 823 \\
2 & 318 \\
244 \\
5 & 473 \\
1 & 058\end{array}$ & $\begin{array}{l}25.37 \\
28.17 \\
26.26 \\
29.43 \\
24.27\end{array}$ & $\begin{array}{r}50588 \\
2256 \\
221 \\
5 \quad 069 \\
833\end{array}$ & $\begin{array}{l}31.43 \\
27.41 \\
23.79 \\
27.17 \\
19.11\end{array}$ & $\begin{array}{r}72026 \\
3 \quad 392 \\
267 \\
6988 \\
\quad 868\end{array}$ \\
\hline $\begin{array}{l}\text { Distrito Federal } \\
\text { Mexico }\end{array}$ & 1132970 & 421367 & 37.19 & 308233 & 27.21 & 403370 & 35.60 & 1210618 \\
\hline $\begin{array}{l}\text { Atizapan de Zaragoza } \\
\text { Ecatepec } \\
\text { Naucalpan } \\
\text { Netzahualcoyotl } \\
\text { La Paz } \\
\text { Texcoco } \\
\text { Tlainepantla } \\
\text { Tolua } \\
\text { Tultitlán }\end{array}$ & $\begin{array}{rl}8 & 493 \\
44550 \\
76 & 901 \\
727 & 902 \\
5 & 917 \\
5 & 048 \\
69 & 291 \\
9 & 306 \\
6 & 805\end{array}$ & $\begin{array}{rl}3 & 977 \\
21 & 010 \\
33 & 656 \\
50 & 679 \\
2 & 478 \\
2 & 222 \\
29 & 392 \\
4 & 183 \\
3 & 025\end{array}$ & $\begin{array}{l}46.83 \\
59.61 \\
43.77 \\
39.65 \\
41.88 \\
44.02 \\
42.42 \\
42.66 \\
44.45\end{array}$ & $\begin{array}{r}2487 \\
12276 \\
22439 \\
38912 \\
1915 \\
1515 \\
19789 \\
2929 \\
1987\end{array}$ & $\begin{array}{l}29.28 \\
21.07 \\
29.18 \\
30.45 \\
32.36 \\
30.01 \\
2.56 \\
24.87 \\
27.73\end{array}$ & $\begin{array}{rl}2 & 025 \\
11 & 256 \\
20 & 806 \\
38 & 211 \\
1 & 524 \\
1 & 311 \\
20 & 110 \\
2 & 694 \\
1 & 893\end{array}$ & $\begin{array}{l}23.89 \\
19032 \\
27.06 \\
29090 \\
25.10 \\
25.97 \\
29002 \\
27.47 \\
27.82\end{array}$ & $\begin{array}{r}1696 \\
9094 \\
20824 \\
27.404 \\
1205 \\
1008 \\
21667 \\
5065 \\
2309\end{array}$ \\
\hline $\begin{array}{l}\text { Nuavo Le } \delta_{n} \\
\text { Santa Catarina } \\
\text { Genoral Escobedo } \\
\text { Apodaca } \\
\text { Guadalupe } \\
\text { Monterrey }\end{array}$ & $\begin{array}{rl}5 & 623 \\
2 & 078 \\
3 & 533 \\
29 & 613 \\
137 & 498\end{array}$ & $\begin{array}{rl}2 & 130 \\
805 \\
1692 \\
10 & 434 \\
52 & 175\end{array}$ & $\begin{array}{l}37.88 \\
39.74 \\
47.89 \\
35.23 \\
37.94\end{array}$ & $\begin{array}{r}1534 \\
568 \\
760 \\
8069 \\
36 \quad 350\end{array}$ & $\begin{array}{l}27.28 \\
27.33 \\
27.51 \\
27.24 \\
26.44\end{array}$ & $\begin{array}{r}1959 \\
705 \\
1081 \\
11 \quad 111 \\
48973\end{array}$ & $\begin{array}{l}34084 \\
33.93 \\
30.60 \\
37.53 \\
35.62\end{array}$ & $\begin{array}{rl}3 & 625 \\
1 & 208 \\
1 & 454 \\
21 & 316 \\
125 & 512\end{array}$ \\
\hline $\begin{array}{l}\text { Tabasco } \\
\text { Cardenas }\end{array}$ & 6157 & 2980 & 48.40 & 1817 & 29.51 & 1360 & 22.09 & 841 \\
\hline $\begin{array}{l}\text { Veracruz } \\
\text { Boca del Rto } \\
\text { J Jestis Carranza } \\
\text { Veracrizz }\end{array}$ & $\begin{array}{rl}1 & 307 \\
2 & 483 \\
19 & 150\end{array}$ & $\begin{array}{r}369 \\
853 \\
7517\end{array}$ & $\begin{array}{l}23.23 \\
34.15 \\
39.25\end{array}$ & $\begin{array}{r}439 \\
632 \\
5334\end{array}$ & $\begin{array}{l}33.59 \\
25.45 \\
27.31\end{array}$ & $\begin{array}{r}499 \\
998 \\
6399\end{array}$ & $\begin{array}{l}38.18 \\
40.20 \\
33.42\end{array}$ & $\begin{array}{r}1301 \\
838 \\
17006\end{array}$ \\
\hline
\end{tabular}

Fuente: Dirección General de Estadística, SIC, Censo General de Población, 1970.

a Este total no incluye a los inmigrantes que tienen 11 años o más de residir en estos municipios. 
mente su fuerza de trabajo, lo que induce cada vez más a los miembros de estas familias a la proletaxización total o parcial.

Según puede deducirse del censo agrícola ganadero y ejidal, el ingreso por parcela ejidal se mantuvo prácticamente constante entre 1960 y 1970 , al pasar de 4090 a 4110 pesos anuales (a precios de 1960). En cuanto a la propiedad privada, la falta de comparabilidad entre las cifras de los censos de 1960 y 1970 impide sacar conclusiones confiables respecto a la tendencia del ingreso y su distribución; sin embargo todo parece indicar que la situación descrita para 1960 por lo menos no ha mejorado y que la mayor parte de estos productores perciben de la actividad agrícola ingresos reducidos en extremo.

Por último, en coincidencia con el estancamiento del sector agrícola (principal fuente de ocupación de la población rural) y como un reflejo de su incapacidad de absorción de nueva mano de obra, el incremento en la migración rural-urbana que se registró durante el decenio anterior, tuvo lugar principalmente a partir de 1966, como lo demuestra el cuadro 14, en el que se incluye la inmigración por años de residencia proveniente de otras entidades hacia los principales municipios urbanos a donde se dirigen las personas que abandonan las áreas rurales. En estos municipios, más del $70 \%$ de los inmigrantes llegaron durante el segundo quinquenio y se concentraron de manera principal en los dos últimos años.

Estas cifras son sólo un indicador parcial del efecto migratorio que ha producido el estancamiento agrícola, puesto que aquí se excluye la migración intraestatal. Asimismo, es probable que las migraciones pendulares a las ciudades que utilizan muchos jornaleros y minifundistas, estén aumentando. Es también factible que la corriente migratoria rural-rural, que se daba todos los años desde áreas agrícolas pobres de distintos lugares del país hacia las regiones productoras de algodón, en los meses de cosecha (si la tendencia a la reducción de la superficie algodonera no se revierte), se torne una corriente rural-urbana. Un efecto similar puede esperarse de la reciente reducción de la supeficie destinada al cultivo de la caña de azúcar.

Poco se conoce acerca de las migraciones pendulares del campo a la ciudad, pese a que un estudio sistemático de las mismas ayudaría a una mayor comprensión del fenómeno del empleo y a que permitiría conocer no sólo una de las alternativas por las que han optado las familias rurales para resolver el problema del desempleo estacional e insuficiencia de ingreso, sino una forma de vinculación entre el sector rura! y el urbano.

\section{Algunas consideraciones SOBRE la política Agrícola ACTUAL}

Se dice que la apertura de nuevas tierras a cultivo es en general cada día más costosa en México, sin embargo, la ineficiencia de una buena parte de la agricultura capitalista -en especial la de los estados del sur y sureste del país- indica que en algunas regiones podría hacerse un 
uso más eficiente de la tierra en beneficio de un grupo mayor de población. Todo parece indicar que se trata (cuando menos en estos casos) más de un problema político que de costos.

A pesar de que las políticas tendientes a elevar los rendimientos de los cultivos - así como el aumento en la disponibilidad de agua para riego- en principio favorecen la absorción de mano de obra, este efecto se ha visto nulificado por el proceso continuo de mecanización, toda vez que el extensionismo y el riego se han concentrado principalmente en la agricultura moderna.

Por otra parte, dada la estructura agraria prevaleciente en México, el proceso de mecanización ha traído como consecuencia principal una reducción en las posibilidades de ocupación de los jornaleros, a quienes el sistema productivo nacional no les ofrece otras alternativas ocupacionales.

A pesar del importante papel que juega el cambio en la composición de cultivos como determinante de la absorción de mano de obra, las medidas de fomento agrícola tendientes a resolver problemas de producción de corto plazo, parecen ignorarlo. Un ejemplo claro de esto es la política de precios de garantía, a veces acompañada de crédito selectivo por cultivos, mediante la cual se trata de impulsar la producción de ciertos bienes agrícolas a fin de satisfacer la demanda creciente que hacen de los mismos otras ramas de actividad, como ha ocurrido con ciertos forrajes y Jleaginosas; o con el objeto de reducir las importaciones de granos básicos cuya compra en el exterior en años recientes haya agravado el problema de la balanza de pagos. Pero no se tiene en cuenta la sustitución entre cultivos que generan este tipo de medidas, en especial cuando la superficie agrícola crece a un ritmo lento, sustitución que en ocasiones crea problemas mayores que aquellos que se intentaba resolver.

Debido a que aquellos productos agrícolas a los que mayor impulso se les ha dado desde principios del decenio de los sesentas, son los grạnos básicos, el sorgo, el cártamo y la soya, los cuales se caracterizan (en especial estos últimos) por su poca intensidad en el uso de mano de obra, su producción ha crecido en detrimento del aumento en la producción (y en ocasiones a costa de la reducción) de cultivos con mayores requerimientos de mano de obra como las hortalizas y el algodón.

Además, como consecuencia de que quienes responden de manera más sensible a las variaciones en los precios relativos de los productos, son quienes producen para el mercado y tienen fácil acceso a él, quienes a su vez son los agricultores que llevan a cabo su producción con mano de obra asalariada; la mencionada sustitución de cultivos ha perjudicado en especial a los jornaleros, cuyas oportunidades de empleo agrícola se han visto reducidas.

De todo lo anterior puede deducirse que si se desea aumentar la demanda de mano de obra con el fin de incrementar (o al menos mantener) el ingreso de las familias rurales más pobres, mientras la mayor parte de la tierra de labor dividida en unidades de explotación de tamaño reditua- 
ble o más que redituable se siga explotando de manera individual, las políticas destinadas a regular la producción agrícola deberán contemplar con cuidado la intensidad en el uso de mano de obra de los distintos cultivos y la sustituibilidad existente entre los mismos.

Además, si la fijación de precios de garantía y las políticas con efectos similares no consideran la sustituibilidad entre cultivos, no sólo se ve amenazado el empleo, sino que es posible que se actúe en contra del objetivo mismo que se persigue, como ocurre cuando el incremento en la producción de cultivos cuya importación se pretende reducir se da mediante la sustitución de cultivos motivo de exportación, con lo que la disminución de las importaciones de productores agrícolas puede eventualmente verse acompañada de reducciones paralelas en las exportaciones, o por lo menos en la tasa de incremento de las mismas.

Una de las principales funciones que ha pretendido darse a los precios de garantía es la de asegurar un ingreso mínimo a los productores pobres, sin embargo, debido a la forma tradicional en que estos comercializan sus productos (vía intermediarios), difícilmente se benefician de la medida; en tanto los agricultores prósperos se ven inducidos a sustituir cultivos que implican mayores riesgos por granos básicos con los que gracias al precio de garantía pueden obtener ganancias relativamente altas y seguras. 